\title{
Microstructure Evolution and Mechanical Properties of As-Cast and As-Compressed ZM6 Magnesium Alloys during the Two-Stage Aging Treatment Process
}

\author{
Jia Fu ${ }^{1,2, * \mathbb{D}}$ and Su Chen ${ }^{1}$ \\ 1 School of Material of Science and Engineering, Xi'an Shiyou University, Xi'an 710065, China; \\ su_chen_vip@163.com \\ 2 School of Material of Science and Engineering, Taiyuan University of Science and Technology, \\ Taiyuan 030024, China \\ * Correspondence: fujia@xsyu.edu.cn
}

Citation: Fu, J.; Chen, S.

Microstructure Evolution and

Mechanical Properties of As-Cast and As-Compressed ZM6 Magnesium Alloys during the Two-Stage Aging Treatment Process. Materials 2021, 14, 7760. https://doi.org/10.3390/ ma14247760

Academic Editor: Kotiba Hamad

Received: 9 November 2021

Accepted: 9 December 2021

Published: 15 December 2021

Publisher's Note: MDPI stays neutral with regard to jurisdictional claims in published maps and institutional affiliations.

Copyright: (c) 2021 by the authors. Licensee MDPI, Basel, Switzerland. This article is an open access article distributed under the terms and conditions of the Creative Commons Attribution (CC BY) license (https:// creativecommons.org/licenses/by/ $4.0 /)$.

\begin{abstract}
In the present study, different solid solution and aging processes of as-cast and ascompressed $\mathrm{ZM} 6\left(\mathrm{Mg}_{2.6} \mathrm{Nd}_{0.4} \mathrm{Zn}_{0.4} \mathrm{Zr}\right)$ alloy were designed, and the microstructure and precipitation strengthening mechanisms were discussed. After the pre-aging treatment, a large amount of G.P. zones formed in the $\alpha-\mathrm{Mg}$ matrix over the course of the subsequent secondary G.P. prescription, where the fine and dispersed $\mathrm{Mg}_{12}(\mathrm{Nd}, \mathrm{Zn})$ phases were precipitated at the grain boundaries. The pre-aging and secondary aging processes resulted in the $\mathrm{Mg}_{12}(\mathrm{Nd}, \mathrm{Zn})$ phase becoming globular, preventing grain boundary sliding and decreasing grain boundary diffusion. Meanwhile, precipitation phase â" $\left(\mathrm{Mg}_{3} \mathrm{Nd}\right)$ demonstrated a coherent relationship with the $\alpha$-Mg matrix after the pre-aging process, and after the secondary aging phase, $\mathrm{Mg}_{12} \mathrm{Nd}$ increases and became semi-coherent in the matrix. Compared to an as-cast ZM6 alloy, the yield strength of the as-compressed ZM6 alloy increased sharply due to an increase in the yield strength that was proportional to the particle spacing, where the dislocation bypassed the second phase particle. Compared to the single-stage aging process, the two-stage aging process greatly improved the mechanical properties of both the as-cast and as-compressed ZM6 alloys. The difference between the as-cast and as-compressed states is that an as-compressed ZM6 alloy with more dislocations and twins has more dispersed precipitates in the G.P. zones after secondary aging, meaning that it is greatly strengthened after the two-stage aging treatment process.
\end{abstract}

Keywords: ZM6 magnesium alloy; heat treatment; microstructure; mechanical properties

\section{Introduction}

The ZM6 alloy (Mg-Nd-Zn-Zr) is a typical magnesium alloy that is strengthened by solid solution and aging processes and that has high strength, a small microporosity tendency, excellent mechanical properties, and good casting properties. Thus, it is commonly used in the aerospace and satellite communication fields due to its obvious age hardening effect [1-4]. Rare earth elements (RE) have a large solid solubility limit in magnesium, and that solid solubility decreases sharply when the temperature decreases, resulting in a large amount of supersaturation being obtained. For magnesium alloys without $\mathrm{Al}$, such as ML10, ZE41, WE43, ZK60, AM-SC1, MRI202S, and ZM6, the grain refinement element is adopted [2-4]. The common heat treatment process is a solution treatment with the addition of artificial aging. The $\mathrm{Mg}-\mathrm{RE}-\mathrm{Zr}$ series alloy can be used at temperatures above $200{ }^{\circ} \mathrm{C}$. As the diffusion rate of RE is slow, a dispersion strengthening phase containing RE can be precipitated in the aging process, which also provides the alloy with high thermal stability and excellent creep resistance [5,6].

The ZM6 alloy is a kind of Mg-Nd-Zn-Zr alloy, and most of the intermetallic compounds that are formed in the RE-Mg binary system are magnesium-rich phases. For light 
rare earth metals, the $\mathrm{REMg}_{2}$ compound is the Laves phase that belongs to the $\mathrm{MgCu}_{2}$ cubic system. Meanwhile, for heavy rare earths, the Laves phase belongs to the $\mathrm{MgZn}_{2}$ hexagonal system $[7,8]$. The stability of these binary phases increases from light rare earth metals to heavy rare earth metals. The Mg-Gd-Nd-Zr and Mg-Gd-Y-Zr alloys have been studied, and the nucleation of the aging phase has been found to be promoted by introducing a large number of dislocations [9]. The precipitation sequence in $\mathrm{Mg}-\mathrm{Gd}-\mathrm{RE}$ is as following: SSSS (super-saturated solid solution) $\rightarrow$ â" $\left(\mathrm{Mg}_{3} \mathrm{Gd}\right.$, hcp, $\left.\mathrm{D}_{19}\right) \rightarrow \hat{a}^{\prime}\left(\mathrm{Mg}_{3} \mathrm{Gd}\right.$, fcc) $\rightarrow \hat{\mathrm{a}}\left(\mathrm{Mg}_{5} \mathrm{Gd}\right.$, fcc) [3]. When the Mg-Gd-Y-Zr alloy is at its peak-aged condition, aging at $200{ }^{\circ} \mathrm{C}$ for $10-16 \mathrm{~h}$ and fine $\hat{a}^{\prime \prime}$ particles with a $\mathrm{D}_{19}$ structure $(a=0.64 \mathrm{~nm}, c=0.52 \mathrm{~nm})$ are the dominant strengthening phase. Moreover, $\hat{a}^{\prime}$ precipitates with an fcc structure $(a=0.742 \mathrm{~nm})$ are the dominant phase in the alloy following over-aging at $250^{\circ} \mathrm{C}$ for $10 \mathrm{~h} \mathrm{[10]}$. Ohishi and $\mathrm{Xu}$ et al. [11,12] studied the transformation mechanism of the precipitated phases in $\mathrm{Mg}-\mathrm{Zn}$ and $\mathrm{Mg}-\mathrm{Al}-\mathrm{Zn}$ alloys during graded aging. It was found that the distribution and morphology of the precipitated phases changed significantly after graded aging compared to after single aging, resulting in the mechanical properties being significantly improved. However, as the aging behavior of the $\mathrm{ZM6}\left(\mathrm{Mg}_{2.6} \mathrm{Nd}_{0.4} \mathrm{Zn}_{0.4} \mathrm{Zr}\right)$ alloy is more complex, there are few reports about the multi-stage aging treatment of magnesium alloys, and their multi-stage aging behavior has not been revealed yet. Therefore, the present study observes the precipitation behavior during the two-stage aging treatment process and the effect of the aging temperature and aging time on the mechanical properties (yield strength, tensile strength and elongation) of both as-cast and as-compressed ZM6 alloys by adjusting and controlling the pre-aging stage during the two-stage aging process. In this paper, the phase composition, microstructure evolution, and age-strengthening mechanism of ZM6 alloys were investigated by means of XRD, DTA, and TEM. The morphology, size and distribution of the precipitation phases were controlled by the TSAT process, and the corresponding mechanical properties were tested through a comparison of those properties under various treatments in order to obtain excellent properties and to provide optimized process parameters for performance control in practical applications.

\section{Materials and Methods}

\subsection{Sample Preparation and Initial Properties of As-Cast and As-Compressed ZM6}

\subsubsection{Casting Process, Chemical Composition, and Hot Compression}

The ZM6 alloy was prepared using pure magnesium ( $\mathrm{Mg} \geq 99.9 \mathrm{wt} \%)$, the $\mathrm{Mg}-25.0 \mathrm{wt} \%$ $\mathrm{Nd}$ master alloy, the Mg-33.3 $\mathrm{wt} \% \mathrm{Zr}$ master alloy, and pure zinc ( $\mathrm{Zn} \geq 99.9 \mathrm{wt} \%)$. The addition of aluminum, iron, silicon, manganese, and magnesium oxide should be avoided because these elements and impurities hinder the grain refinement in zirconium. During the smelting process, the alloy was melted in a resistance furnace and was protected by $\mathrm{CO}_{2}$ and $\mathrm{SF}_{6}$ gas in order to ensure that the alloy liquid did not become oxidized, thereby reducing the loss of alloy elements by burning and improving the casting quality. The test alloy was added in the form of a mixed rare earth metal and was dried at $200{ }^{\circ} \mathrm{C}$ before casting, and it was then melted in a steam crucible furnace. The crucible and the other tools were cleaned and preheated with flux before use, and they were then cast in a metal mold. The ingot was preheated in a preheated crucible at $200^{\circ} \mathrm{C}$ and kept at $720{ }^{\circ} \mathrm{C}$ for 25-30 min. After the alloy was completely melted, the pure $\mathrm{Zn}$ and $\mathrm{Mg}-\mathrm{Nd}$ master alloys were added at $750{ }^{\circ} \mathrm{C}$ and were held there for $5 \mathrm{~min}$; then, the $\mathrm{Mg}$ - $\mathrm{Zr}$ master alloys were added at $780^{\circ} \mathrm{C}$ and were kept there $5 \mathrm{~min}$, and then the $1 \%$ refining agent was added and stirred. Finally, the master alloys were kept at $780{ }^{\circ} \mathrm{C}$ for $20 \mathrm{~min}$, and the metal mould $(160 \mathrm{~mm} \times 130 \mathrm{~mm} \times 20 \mathrm{~mm})$ was poured at $720^{\circ} \mathrm{C}$.

The chemical composition of the as-cast $\mathrm{ZM} 6\left(\mathrm{Mg}_{2.6} \mathrm{Nd}_{0.4} \mathrm{Zn}_{0.4} \mathrm{Zr}\right)$ alloy was within the standard content region as follows: $0.2-0.7 \% \mathrm{Zn}, 2.0-3.0 \% \mathrm{Nd}, 0.4-1.0 \% \mathrm{Zr}, \mathrm{Si}: 0.01 \%, \mathrm{Cu}$ : $0.03 \%$, Ni: $0.01 \%$, Fe: $0.01 \%$, others: $0.05 \%$ (all in mass fraction). The as-cast bar stock was then compressed at $400-450{ }^{\circ} \mathrm{C}$ and at a compression degree of $8 \%$. The tensile strength and the elongation of the as-cast and as-compressed ZM6 heat-resistant magnesium alloys were tested by the vendor of the Xi'an Brake Branch of Avic Aircraft Co., Ltd. (Xi'an, China). 


\subsubsection{Mechanical Properties of As-Cast and As-Compressed ZM6}

The mechanical properties of the as-cast and as-compressed ZM6 are listed in Table 1.

Table 1. Tensile properties and hardness of as-cast and as-compressed ZM6 alloys.

\begin{tabular}{cccccc}
\hline & \multicolumn{3}{c}{ Tensile Properties } & Hardness \\
\hline & $\boldsymbol{\sigma}_{\mathbf{b}} \mathbf{( M P a )}$ & $\boldsymbol{\sigma}_{\mathbf{0 . 2}} \mathbf{( M P a )}$ & $\boldsymbol{\delta} \mathbf{( \% )}$ & $\boldsymbol{\sigma} \mathbf{( \% )}$ & $\mathbf{H V}$ \\
\hline As-cast ZM6 & 153.36 & 108.13 & 3.14 & 4.5 & 54.12 \\
As-compressed ZM6 & 232.16 & 139.75 & 10.97 & - & 63.26 \\
\hline
\end{tabular}

From Table 1, the as-cast ZM6 showed a surface area reduction of $4.5 \%$. Before the heat treatment, the tensile strength, yield strength, and elongation properties of the ascompressed specimens increased by $78.74 \mathrm{MPa}, 31.62 \mathrm{MPa}$, and $7.83 \%$ compared to the as-cast properties. The mechanical properties of the as-cast and as-compressed ZM6 alloys were provided by the vendor of the Xi'an Brake Branch of Avic Aircraft Co., Ltd.

\subsection{Experimental Heat Treatment Schedules and Property Measurements}

\subsubsection{Heat Treatment Schedules of As-Cast and As-Compressed ZM6}

The as-cast and as-compressed ZM6 were used to prepare specimens using the DK7740 wire cutting machine (Jiangsu Fangzheng CNC Machine Tool Co., Ltd., Taizhou, China), which was operated with a voltage of $5.0 \mathrm{~V}$ and a current of 2.2 A. Sample dimensions for the heat treatment and tensile test are shown in Figure 1.

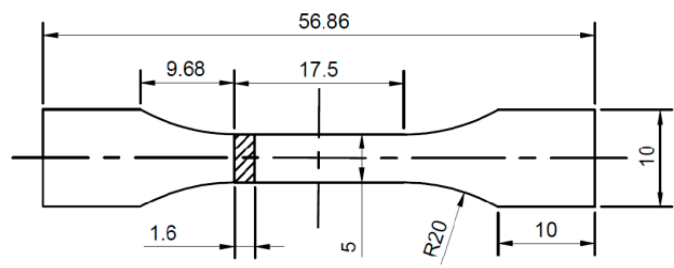

(a)

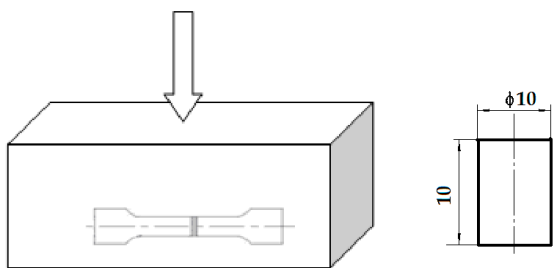

(b)

Figure 1. Sample dimensions: (a) Sample dimensions for tensile test; (b) pre-compressed deformation for tensile test and sample dimensions for solid solution and aging process.

The tensile sample had the flat section size that is seen in GB/T1177-2018 (the specifications are as in Figure 1a), and the tensile rate was $1 \times 10^{-3} \mathrm{~s}^{-1}$. The pre-compressed cylindrical samples had a diameter of $10 \pm 0.05 \mathrm{~mm}$ and a length of $10 \pm 0.05 \mathrm{~mm}$, as seen in Figure $1 b$.

The ZM6 samples were heated in the KF1600-I box resistance furnace (Tianjin Mafuer Technology Co., Ltd., Tianjin, China) with a heating rate of $7{ }^{\circ} \mathrm{C} / \mathrm{min}$. The protective agent that was used during the heat treatment process was iron sulfide (pyrite). Among processes, the T4 process was treated using a solid solution $\left(525^{\circ} \mathrm{C} \times 4 \mathrm{~h}\right)$, and the T5 process was treated through aging $\left(200^{\circ} \mathrm{C} \times 8 \mathrm{~h}\right)$ without the use of a solid solution. The T6 process was treated using a solid solution at $525^{\circ} \mathrm{C}$ for $4.0 \mathrm{~h}$ and through aging at different aging temperatures and aging times. Both the as-cast and as-compressed samples were studied under four different conditions in order to find the effect of the aging temperature and the aging time on their mechanical properties. The heat treatment schedules of the as-cast and as-compressed ZM6 samples that were designed and carried out are listed in Table 2.

From Table 2, the specimens that were in both states were tested simultaneously, and meanwhile, the T6 single-stage aging treatment (T6_SSAT) samples and T6 with two-stageaging treatment (T6_TSAT) samples were measured and discussed for comparison. For the TSAT process, the pre-aging process comprised heating at $200-300{ }^{\circ} \mathrm{C}$ with a holding time of $0.05-0.25 \mathrm{~h}$, and the final-stage aging was at $200^{\circ} \mathrm{C}$ with a holding time of $8.25 \mathrm{~h}$. The T6 heat treatment process is usually adopted, and the solid solution process that is 
usually chosen for experiments is $525^{\circ} \mathrm{C}$ for $4 \mathrm{~h}$ with cooling at $80^{\circ} \mathrm{C}$ or above, which can completely dissolve the second phase into the matrix to obtain a supersaturated solid solution. For the SSAT process, the aging temperature was $100-400{ }^{\circ} \mathrm{C}$ with temperature intervals of $100{ }^{\circ} \mathrm{C}$ that were obtained by air cooling. For the TSAT process, the pre-aging temperature was $200-300^{\circ} \mathrm{C}$ with temperature intervals of $25^{\circ} \mathrm{C}$ that were obtained air cooling, the pre-aging times were $0.05 \mathrm{~h}, 0.10 \mathrm{~h}, 0.15 \mathrm{~h}, 0.20 \mathrm{~h}$, and $0.25 \mathrm{~h}$, and then the secondary aging treatment $\left(200{ }^{\circ} \mathrm{C} \times 8 \mathrm{~h}\right)$ was carried out. The T6_SSAT process took place at $200{ }^{\circ} \mathrm{C} \times 8.25 \mathrm{~h}$, and the T6_TSAT process took place at $200-350{ }^{\circ} \mathrm{C} \times 0.05-0.25 \mathrm{~h}$ and $200{ }^{\circ} \mathrm{C} \times 8 \mathrm{~h}$. When both the as-cast T6 and as-compressed T6 samples were aging at $200{ }^{\circ} \mathrm{C}$ for $0-64 \mathrm{~h}$, the aging times were chosen to be $0 \mathrm{~h}, 4 \mathrm{~h}, 8 \mathrm{~h}, 12 \mathrm{~h}, 16 \mathrm{~h}, 20 \mathrm{~h}, 32 \mathrm{~h}$, and $64 \mathrm{~h}$.

Table 2. Schedules for the heat treatment experiments of the ZM6 alloys.

\begin{tabular}{|c|c|c|c|c|c|}
\hline \multirow[b]{2}{*}{ Condition } & \multicolumn{2}{|c|}{ Single-Stage Aging of ZM6 } & \multicolumn{3}{|c|}{ Two-Stage Aging of ZM6 } \\
\hline & Solid Solution & Aging Process & Solid Solution & Pre-Aging Process & Final-Stage Aging Process \\
\hline As-cast T5 & - & $200^{\circ} \mathrm{C} \times 8.25 \mathrm{~h}$ & - & $275{ }^{\circ} \mathrm{C} \times 0.25 \mathrm{~h}$ & $200{ }^{\circ} \mathrm{C} \times 8 \mathrm{~h}$ \\
\hline As-cast T6 & $525^{\circ} \mathrm{C} \times 4 \mathrm{~h}$ & $100-400{ }^{\circ} \mathrm{C} \times 8.25 \mathrm{~h}$ & $525^{\circ} \mathrm{C} \times 4 \mathrm{~h}$ & $200-350{ }^{\circ} \mathrm{C} \times 0.05-0.25 \mathrm{~h}$ & $200{ }^{\circ} \mathrm{C} \times 0-64 \mathrm{~h}$ \\
\hline As-compressed T4 & $525^{\circ} \mathrm{C} \times 4 \mathrm{~h}$ & - & $525^{\circ} \mathrm{C} \times 4 \mathrm{~h}$ & - & - \\
\hline As-compressed T5 & - & $200^{\circ} \mathrm{C} \times 8.25 \mathrm{~h}$ & - & $275^{\circ} \mathrm{C} \times 0.25 \mathrm{~h}$ & $200^{\circ} \mathrm{C} \times 8 \mathrm{~h}$ \\
\hline As-compressed T6 & $525^{\circ} \mathrm{C} \times 4 \mathrm{~h}$ & $100-400{ }^{\circ} \mathrm{C} \times 8.25 \mathrm{~h}$ & $525^{\circ} \mathrm{C} \times 4 \mathrm{~h}$ & $200-350{ }^{\circ} \mathrm{C} \times 0.05-0.25 \mathrm{~h}$ & $200{ }^{\circ} \mathrm{C} \times 0-64 \mathrm{~h}$ \\
\hline
\end{tabular}

\subsubsection{Microstructure Analysis and Mechanical Properties Measurement}

After the solid solution and aging processes outlined in Table 2, each specimen was polished and etched with a specific etchant $(10 \mathrm{~mL}$ acetic acid $+4.2 \mathrm{~g}$ picric acid $+10 \mathrm{~mL}$ $\mathrm{H}_{2} \mathrm{O}+70 \mathrm{~mL}$ ethanol) or with a $4 \%$ nitric acid alcohol solution for about 3-5 s. The as-cast, as-compressed, and heat-treated specimens were inlaid with cold-setting epoxy resin. The grain size was measured using the ASTM E112-88 chord length method in polarized light mode with no less than 200 grains. The precipitate phases were observed and analyzed by means of an XRD-6000 X-ray diffractometer (Shimadzu Corporation, Tokyo, Japan), a VHX-600E optical microscope (OM) (KEYENCE Co., Ltd., Osaka, Japan), a JSM-7100F scanning electron microscope (SEM) (JEOL Ltd., Tokyo, Japan) with an Oxford AZtecX-Max20 energy spectrum probe (Oxford Instruments, Oxford, UK) for the energy dispersive spectroscopy (EDS) analysis and with a JEM-2100Plus transmission electron microscope (TEM) (JEOL Ltd., Tokyo, Japan) after ion thinning. Hardness was measured using the Vickers hardness tester (the load was $50 \mathrm{gf}$, the dwell time was about $15 \mathrm{~s}$, the spacing between indentations was about $0.1 \mathrm{~mm}$ ). Moreover, V-notched Charpy-notched specimens that were $5 \mathrm{~mm} \times 10 \mathrm{~mm} \times 55 \mathrm{~mm}$ (GB/T229-1994) in size were tested to measure the toughness. Each specimen was tested three times and then averaged. The hardness, elongation, and impact toughness were determined using the FM-700/SVDM4R microhardness tester (Future Tech Enterprise Inc., New York, USA), the FLFS-105 slow strain rate tensile tester (FULE Instrument Technology Co., Ltd., Shanghai, China), and the C64-305 MTS universal tester (MTS Systems (China) Co., Ltd., Eden Prairie, MN, USA), respectively. The liquidus and solidus temperatures of the $\mathrm{Mg}-\mathrm{Nd}-\mathrm{Zn}-\mathrm{Zr}$ alloy during the cooling process were analyzed using a TGA/DSC 3 + differential thermal analyzer (Mettler Toledo, Zurich, Switzerland).

\section{Results and Discussion}

\subsection{Analysis of the Alloy Phase Diagram and Initial Microstructures}

The ZM6 alloy is a high-temperature magnesium alloy that is of a similar composition and that has similar properties to the ZE41A alloy and RZ5 alloys. The Zn content in the designed ZM6 alloy was low and completely dissolved in $\alpha$-Mg matrix. The ZM6 that was used in this study was analyzed by Inductively Coupled Plasma (ICPS-1000 III) as being $2.58 \mathrm{Nd} \%, 0.36 \mathrm{Zn} \%$, and $0.44 \mathrm{Zr} \%$ (dissolved $\mathrm{Zr}$ ). 


\subsubsection{Alloy Phase Diagram Analysis of Mg-Nd-Zn-Zr Alloy}

The representative two binary phase diagrams of the $\mathrm{Zn}-\mathrm{Mg}$, Nd-Mg [13], $\mathrm{Zr}-\mathrm{Mg}$ [14], and $\mathrm{Mg}-\mathrm{Nd}-\mathrm{Zn}-\mathrm{Zr}$ alloys are shown in Figure 2.

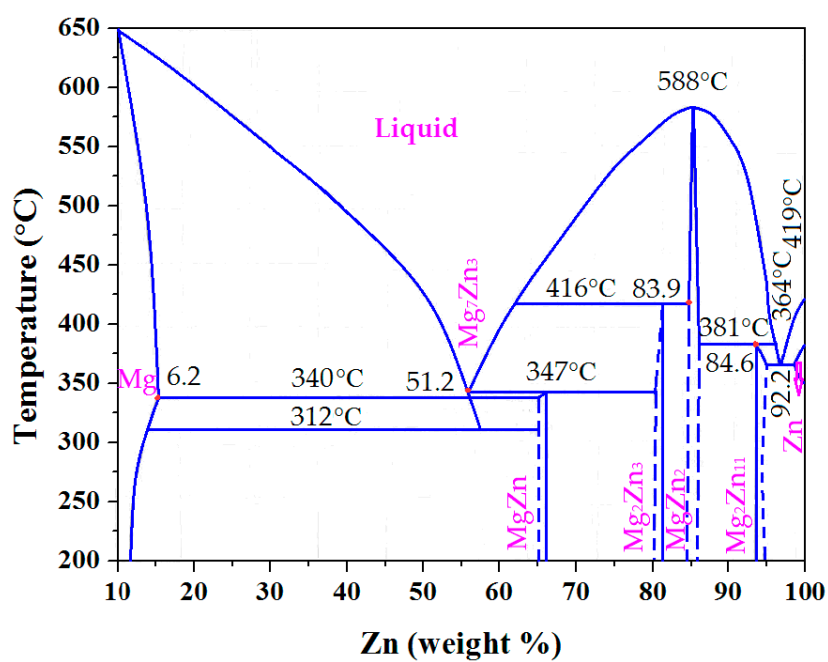

(a)

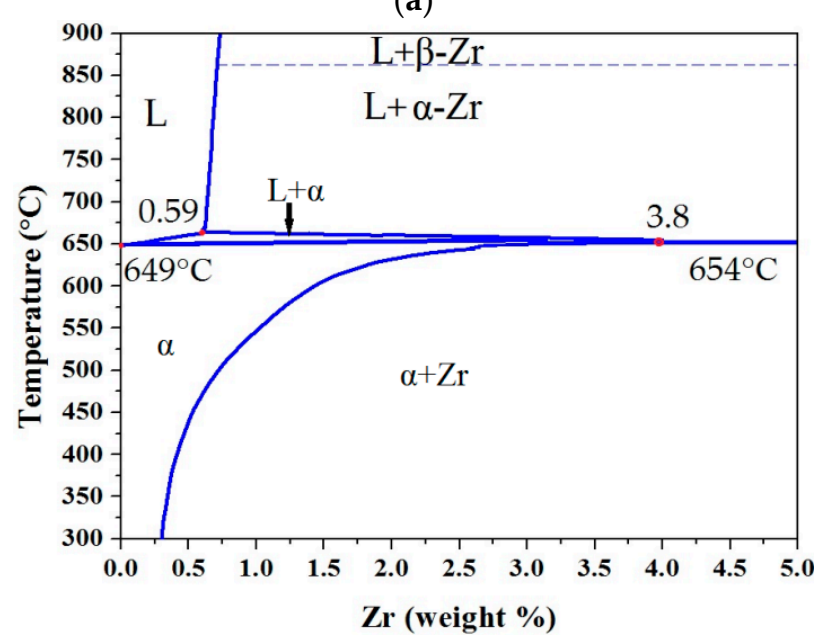

(c)

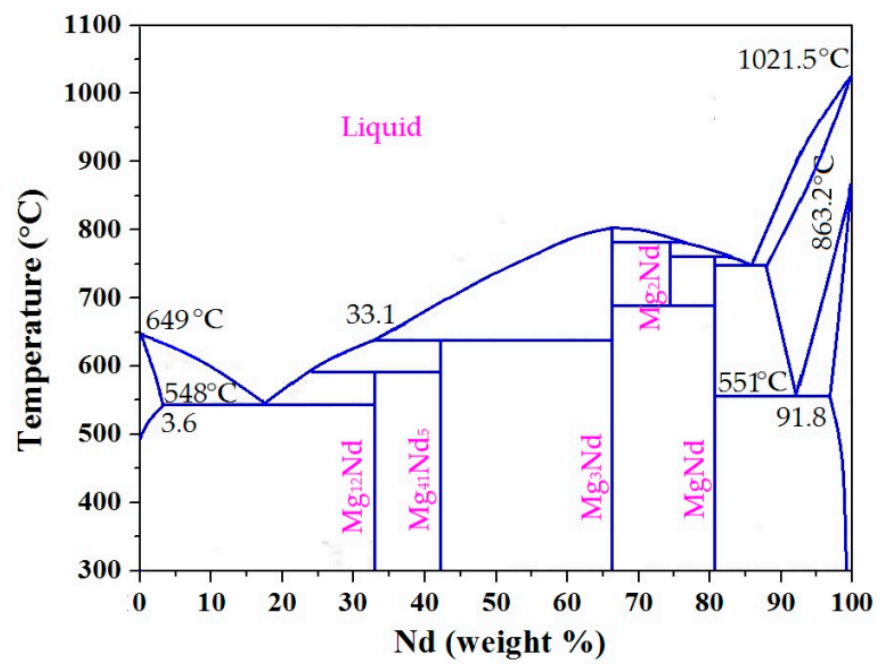

(b)

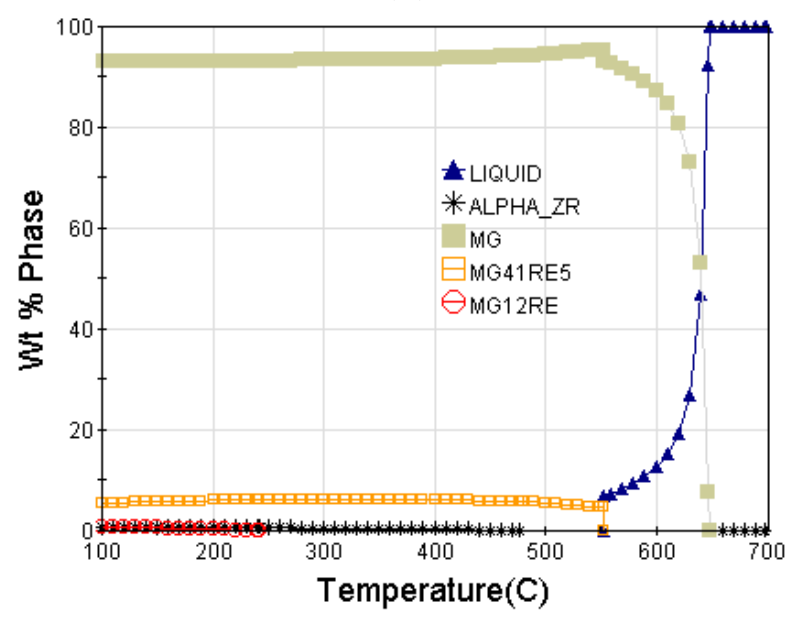

(d)

Figure 2. Solidification of binary and ternary phase diagrams: (a) Phase diagram of Mg-Zn alloy; (b) phase diagram of $\mathrm{Mg}-\mathrm{Nd}$ alloy; (c) phase diagram of $\mathrm{Mg}-\mathrm{Zr}$ alloy; (d) phase diagram of $\mathrm{ZM} 6\left(\mathrm{Mg}_{2.6} \mathrm{Nd}_{0.4} \mathrm{Zn}_{0.4} \mathrm{Zr}\right)$ alloy.

From Figure 2a, according to the Mg-Zn binary phase diagram, the maximum solubility of $\mathrm{Zn}$ in $\mathrm{Mg}$ is $6.18 \mathrm{wt} \%$ under equilibrium conditions. As the composition of the $\mathrm{Zn}$ element in the $\mathrm{ZM} 6\left(\mathrm{Mg}_{2.6} \mathrm{Nd}_{0.4} \mathrm{Zn}_{0.4} \mathrm{Zr}\right)$ alloy was $4 \%$, which is under the equilibrium solidification condition, all of the $\mathrm{Zn}$ was dissolved in the $\mathrm{Mg}$ matrix, and the solidification rate of $\mathrm{Zn}$ was much higher than that of equilibrium solidification, with a small $\mathrm{Mg}-\mathrm{Zn}$ mesophase being present along the grain boundary [10]. As seen in Figure 2b, the formed precipitated-phase $\mathrm{Mg}_{12} \mathrm{Nd}$ contained a large number of $\mathrm{Mg}$ atoms with a high melting point and good thermal stability $[10,13]$. Generally, the melting points of rare earth elements are relatively high, reaching $798-1663{ }^{\circ} \mathrm{C}$, and their diffusion in the $\mathrm{Mg}$ matrix is relatively slower [2,3]. The strength of the $\mathrm{Mg}-\mathrm{Nd}-\mathrm{Zn}-\mathrm{Zr}$ alloy increased by $0.5-1$ times, and the limiting temperature increased to $350{ }^{\circ} \mathrm{C}$ compared to the AZ31 alloy [10]. $\mathrm{Nd}$ can improve the creep strength of the ZM6 alloy [10]. Figure 2c shows the Mg-Zr phase diagram and demonstrates that the peritectic reaction took place at $649^{\circ} \mathrm{C}$, when the $\mathrm{Zr}$ content was 0.58 . It should be noted that the $\mathrm{Zr}$ content at the peritectic reaction point varied from 0.50 to 0.76 in different alloys, demonstrating an obvious grain refinement effect [14]. However, this diagram cannot explain the alloy that had a $\mathrm{Zr}$ content of less 
than $0.58 \%$. The $\mathrm{Zr}$ addition amount should be $3-5$ times that of the dissolved $\mathrm{Zr}$, that is, the amount of $\mathrm{Zr}$ that is added in the $\mathrm{ZM} 6$ alloy should be $1.32-2.2 \%$ during the casting process. As seen in Figure 2d, the ZM6 alloy phase diagram is composed of the liquid zone, the $\mathrm{Mg}$ matrix, $\alpha-\mathrm{Zr}, \mathrm{Mg}_{41} \mathrm{RE}_{5}$, and $\mathrm{Mg}_{12} \mathrm{RE}$. For the $\mathrm{ZM} 6$ alloy, the composition of the magnesium-rich compound $\mathrm{REMg}_{12}$ for the light rare earth metals and $\mathrm{RE}_{5} \mathrm{Mg}_{24}$ for the trivalent heavy rare earth metals formed a eutectic equilibrium with $\mathrm{Mg}$. The $\mathrm{Mg}_{12} \mathrm{RE}$ phase exists below $234.6{ }^{\circ} \mathrm{C}$. The pouring temperature should be above the liquid point of $549.5{ }^{\circ} \mathrm{C}$.

In order to reduce the hot cracking tendency that $\mathrm{Mg}-\mathrm{Zn}-\mathrm{Zr}$ alloys have, the rare earth metal Nd was added into the ZM6 alloy, which dissolved in the Mg matrix. At the magnesium-rich end, the peritectic reaction and the solid-phase transformation occurs more easily, so a metastable alloy can be easily formed at this end. As the melting points of the rare earth metals increase, the phase diagram shows a smooth change, and several rare earth compounds gradually disappear. The addition of $\mathrm{Nd}(2.0-3.0 \%)$ greatly reduces the solid solubility of zinc in magnesium, and the eutectic that is distributed in the grain boundary is brittle. The higher the content of rare earth elements in the alloy is, the better the casting properties are, but the mechanicals properties will be lower.

\subsubsection{DTA Thermal Analysis Curve and Characteristic Temperatures}

In the eutectic equilibrium state, the eutectic composition of the compound changes gradually along with the atomic number of the RE element, and the solubility of the RE in the solid $\mathrm{Mg}$ decreases gradually as the atomic radius of the RE element increases. The first derivative of the cooling curve is $d T_{\mathcal{c}} / d t$, which is related to the solidification reactions for the different phases, which can be determined to determine the critical solidification characteristics of as-cast $\mathrm{ZM} 6$ alloys. The heating temperature was $780^{\circ} \mathrm{C}$, and the heating speed was $40^{\circ} \mathrm{C} / \mathrm{min}$. Figure 3 shows the differential thermal analysis (DTA) curves of the as-cast and as-compressed ZM6 alloys.

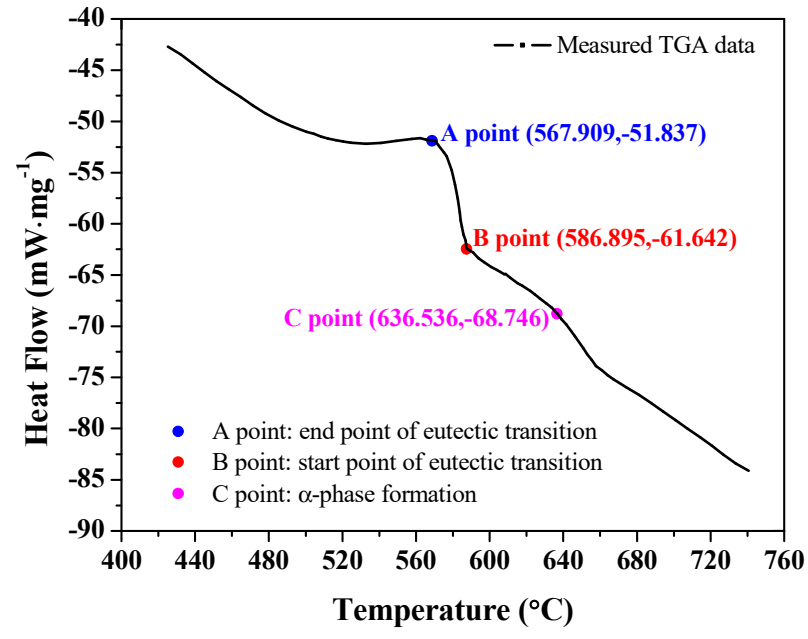

(a)

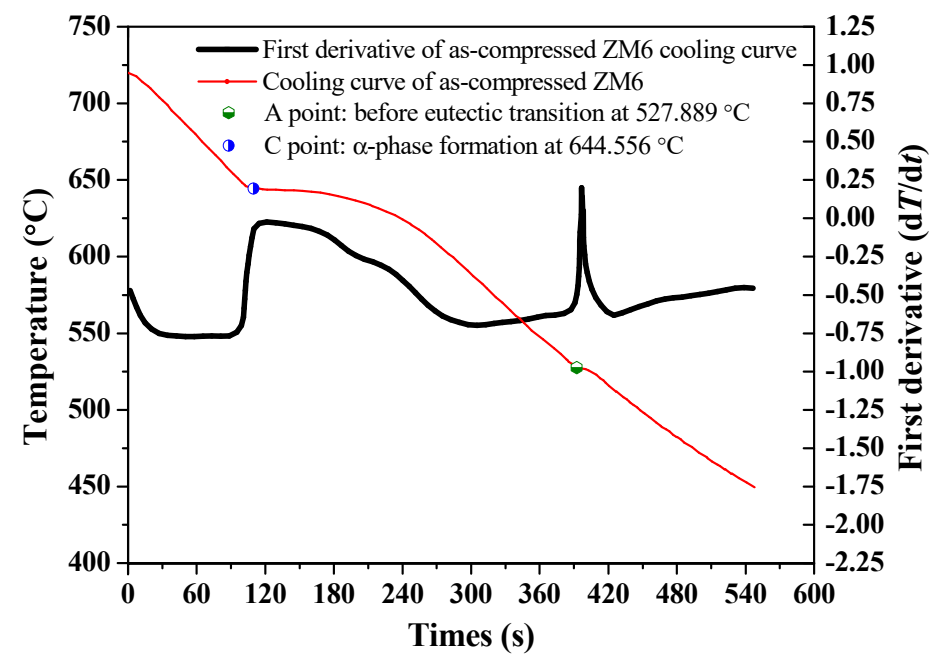

(b)

Figure 3. DTA curve: (a) DTA curve of the as-cast ZM6 alloy; (b) DTA curve of the as-compressed ZM6 alloy.

From Figure 3a, when the temperature reaches at $636.54{ }^{\circ} \mathrm{C}$, the elements in as-cast ZM6 alloy are all dissolved, and the eutectic transition occurs between $567.91{ }^{\circ} \mathrm{C}$ and $586.90{ }^{\circ} \mathrm{C}$. It can be observed from Figure $3 \mathrm{~b}$ that two defined peaks are present in the as-compressed ZM6 alloy. The ZM6 alloy consists of dissolved $\mathrm{Zn}$ and RE in $\alpha$-Mg matrix and a small eutectic Mg-Zn phase, Mg-RE phase, and Mg-Zn-RE phase. Due to the addition of RE elements, a certain number of eutectic compounds are formed. When the temperature is cooled to the primary $\alpha-\mathrm{Mg}$ phase formation reaction at $644.56^{\circ} \mathrm{C}$ (point $\mathrm{A}$ ), the nonequilibrium eutectic reaction occurs at $560^{\circ} \mathrm{C}$ [15] and ends at $527.89^{\circ} \mathrm{C}$, resulting in 
$\mathrm{Mg}_{12} \mathrm{Nd}$ compounds being obtained. The temperature of the whole eutectic reaction is within the range of $567.91 \pm 10^{\circ} \mathrm{C}$.

\subsection{Microstructure and Phase Analysis after the Single and Two-Stage Aging Processes}

The microstructures and XRD comparisons for the as-cast, as-compressed (A.C.), and A.C. T6_SSAT ZM6 alloys are shown in Figure 4.

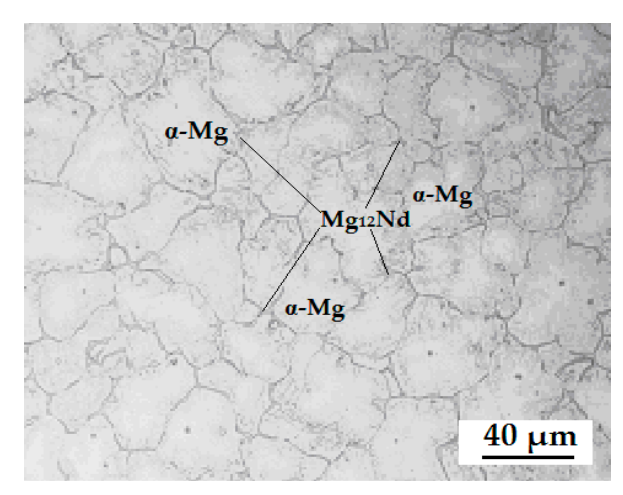

(a)

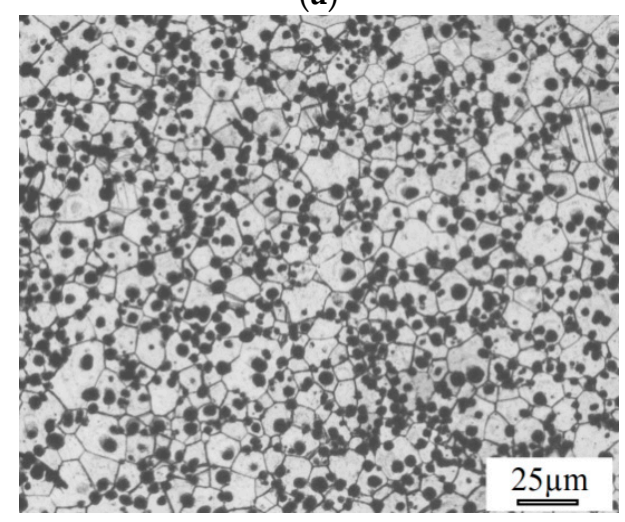

(c)

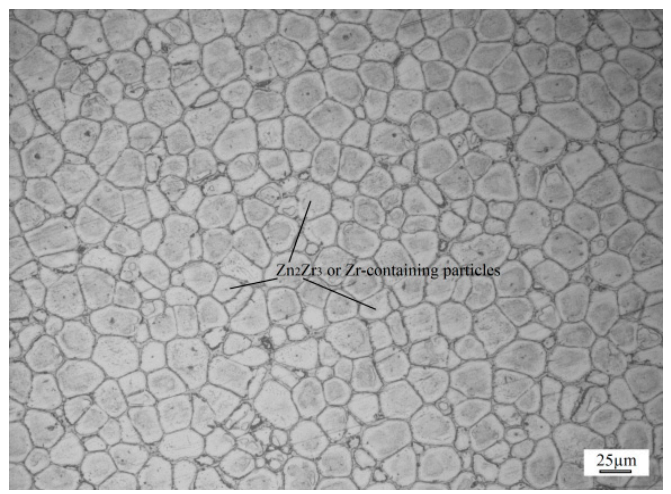

(b)

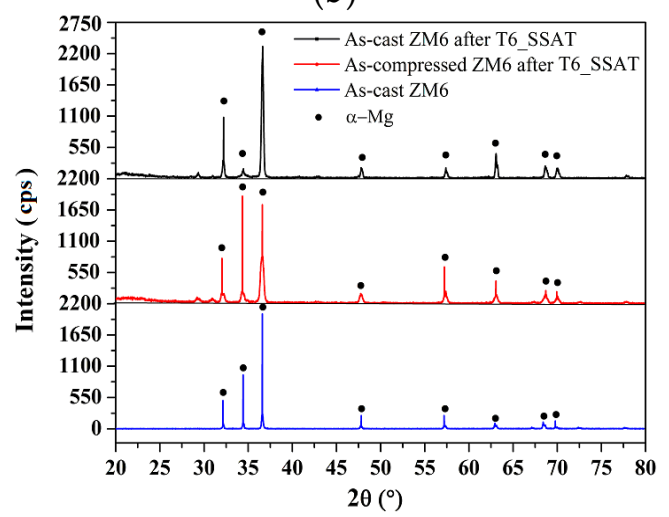

(d)

Figure 4. OM and XRD analysis using different heat treatment methods: (a) As-cast ZM6 alloy; (b) as-compressed ZM6 alloy; (c) as-compressed ZM6 alloy with T6_SSAT process; (d) XRD comparison of ZM6 alloys with T6_SSAT process.

Figure 4a demonstrates that the as-cast microstructure is composed of two parts: a grey $\alpha$ matrix and a white island $\mathrm{Mg}_{12} \mathrm{Nd}$ phase that are distributed at the grain boundary. The $\beta$ phase $\left(\mathrm{Mg}_{12} \mathrm{Nd}\right)$ exists at the grain boundary on its own, and the average grain size is about $40.5 \mu \mathrm{m}$. In Figure $4 \mathrm{~b}$, the grain is remarkably refined and is uniformly distributed after hot compression. The grain boundary phase is broken, dispersed, and then refined, with an average grain size of $25.6 \mu \mathrm{m}$, which is in contrast with the almost chrysanthemumshaped grains that are seen in the as-cast ZM6 alloy. The cotton-wadding shape inside the grain is considered to be $\mathrm{ZnZr}_{3}$ or $\mathrm{Zr}$-containing particles [16]. The small grains are mainly formed by slip and twinning, and the continuous dislocation movement along the slip surface promotes the nucleation of the aging phase. As seen in Figure 4c, the second phase disappeared at the grain boundary and was replaced by the dispersed cluster precipitates, most of which were distributed in the grain boundary. The eutectic phase was distributed on the grain boundaries in the form of islands, the shape of which depends on the growth of the primary $\alpha-\mathrm{Mg}$ phase $[2,10,13]$. The grain boundary is shown to be clear and regular, and the strip phase near the grain boundaries no longer exists. From the XRD comparison analysis of the ZM6 alloys in Figure $4 \mathrm{~d}$, only the $\alpha-\mathrm{Mg}$ matrix and $\mathrm{Mg}_{12} \mathrm{Nd}$ compounds can be detected, and the main diffraction peaks are all $\mathrm{Mg}$ diffraction peaks. It is evident from Figure $4 \mathrm{~d}$ that the as-compressed specimen with the T6_SSAT process has more texture compared to the as-cast specimen, which has a marked effect on mechanical properties. 


\subsubsection{SEM and TEM Analysis after Aging Treatments}

Taking the two-step aging process as an example, the microstructures of the as-cast ZM6 alloy under various aging temperatures and aging times are shown in Figure 5.

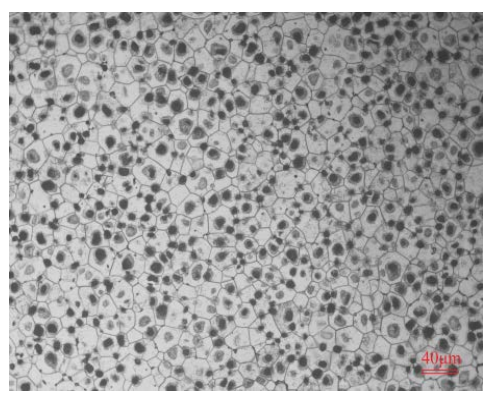

(a)

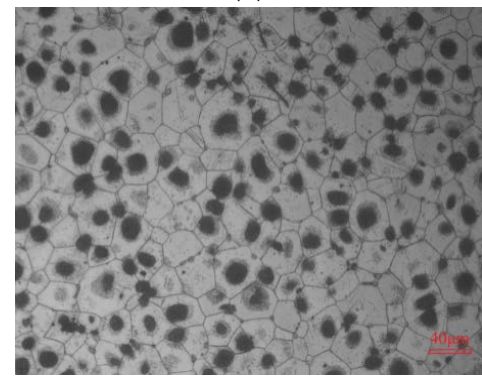

(c)

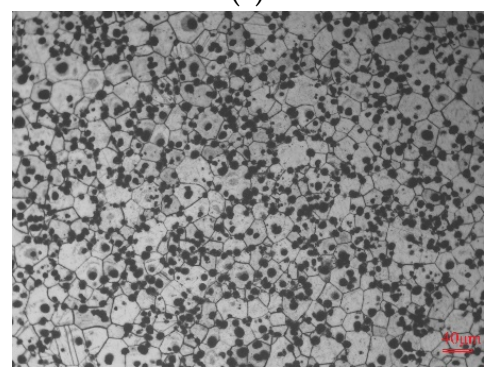

(e)

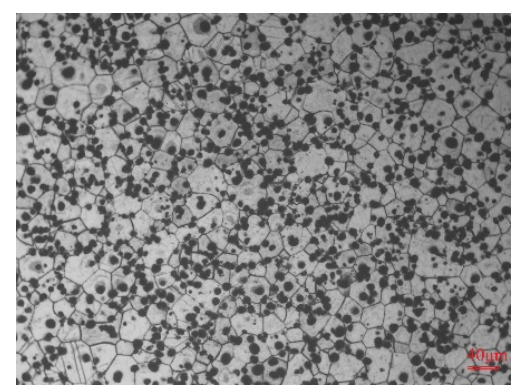

(b)

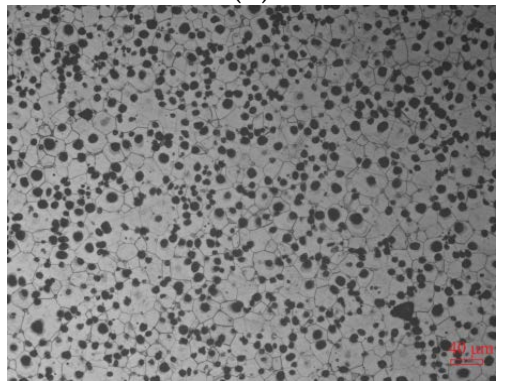

(d)

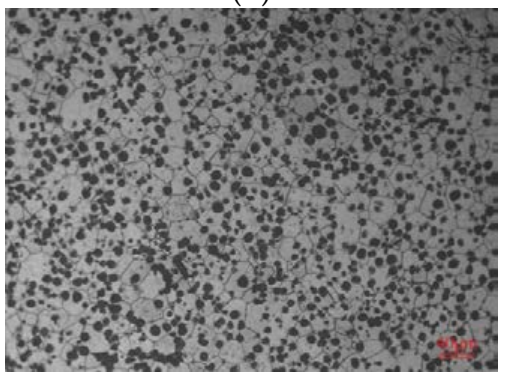

(f)

Figure 5. Microstructure of as-cast ZM6 alloy with different pre-aging temperatures and pre-aging times: (a) $250{ }^{\circ} \mathrm{C} \times$ $0.20 \mathrm{~h}+200{ }^{\circ} \mathrm{C} \times 8 \mathrm{~h} ;$ (b) $275^{\circ} \mathrm{C} \times 0.20 \mathrm{~h}+200^{\circ} \mathrm{C} \times 8 \mathrm{~h}$; (c) $300{ }^{\circ} \mathrm{C} \times 0.20 \mathrm{~h}+200{ }^{\circ} \mathrm{C} \times 8 \mathrm{~h} ;\left(\right.$ d) $275^{\circ} \mathrm{C} \times 0.15 \mathrm{~h}+200{ }^{\circ} \mathrm{C} \times$ $8 \mathrm{~h}$; (e) $275^{\circ} \mathrm{C} \times 0.20 \mathrm{~h}+200^{\circ} \mathrm{C} \times 8 \mathrm{~h}$; and (f) $275^{\circ} \mathrm{C} \times 0.25 \mathrm{~h}+200^{\circ} \mathrm{C} \times 8 \mathrm{~h}$.

Figure $5 \mathrm{a}-\mathrm{c}$ are the microstructures after pre-aging at $250{ }^{\circ} \mathrm{C}, 275{ }^{\circ} \mathrm{C}$, and $300{ }^{\circ} \mathrm{C}$ with the holding time of $0.20 \mathrm{~h}$, respectively, which are composed of polycrystalline $\alpha-\mathrm{Mg}$ and are unevenly distributed cluster precipitates. A spherical phase exists in the grain. From Figure 5a, the grain shape changes from a chrysanthemum-shaped to hexagonal structure, and the average grain size increases slightly, from $39.6 \mu \mathrm{m}$ to $41.0 \mu \mathrm{m}$. Figure $5 \mathrm{~d}-\mathrm{f}$ correspond to microstructures that have been pre-aged at $275^{\circ} \mathrm{C}$ for $0.15,0.20$, and $0.25 \mathrm{~h}$ and then re-aged at $200{ }^{\circ} \mathrm{C}$ for $8 \mathrm{~h}$; the microstructures show cluster-like precipitates that are still inhomogeneous and that are dispersed in the $\alpha-\mathrm{Mg}$ solid solution. It can be seen from Figure $4 \mathrm{~b}$ that that $\mathrm{Mg}_{12} \mathrm{Nd}$ compounds are around the $\alpha-\mathrm{Mg}$ grain boundaries and demonstrate a coarse network morphology with spicule and rod-shaped phases $[17,18]$. It can be seen that after the final aging step, the average grain size of the as-cast ZM 6 is $39.6-41.5 \mu \mathrm{m}$, and the average grain size increases slightly when the pre-aging time is prolonged. Moreover, the effect of the pre-aging temperature on the average grain size is greater than that of the pre-aging time.

The TEM and HRTEM of the as-compressed samples with SSAT at $250-300{ }^{\circ} \mathrm{C}$ for $8.25 \mathrm{~h}$ and TSAT at $275{ }^{\circ} \mathrm{C}$ for $0.15-0.25 \mathrm{~h}+200{ }^{\circ} \mathrm{C}$ for $8 \mathrm{~h}$ were analyzed, as shown in Figure 6. 


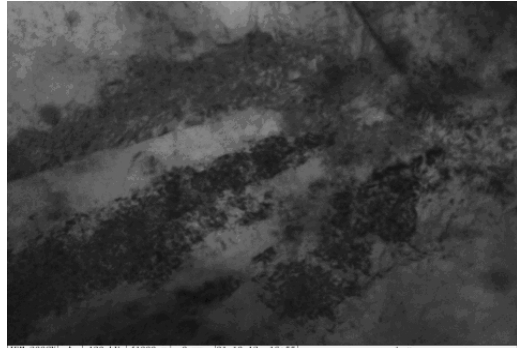

(a)

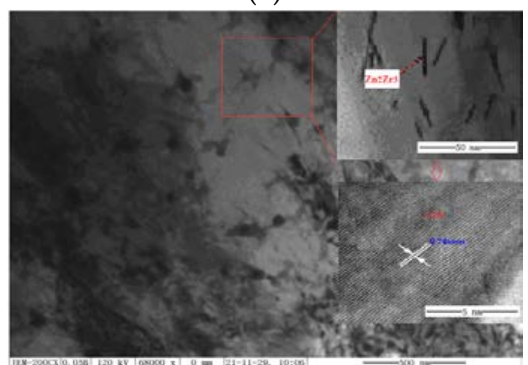

$€$

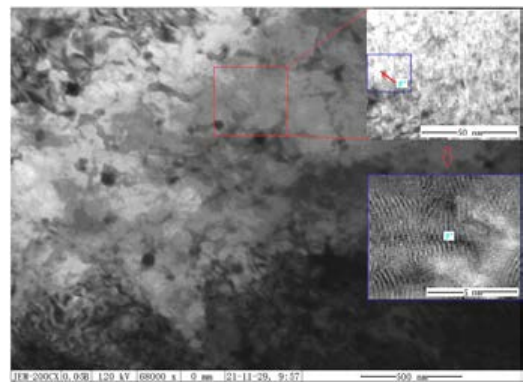

(e)

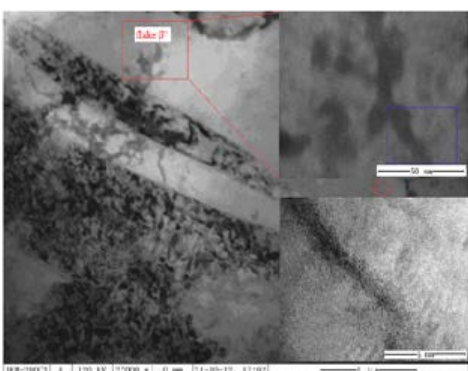

(b)

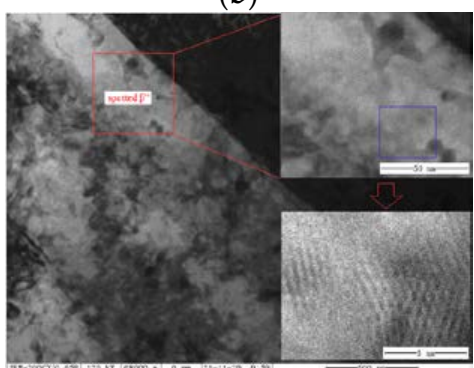

(d)

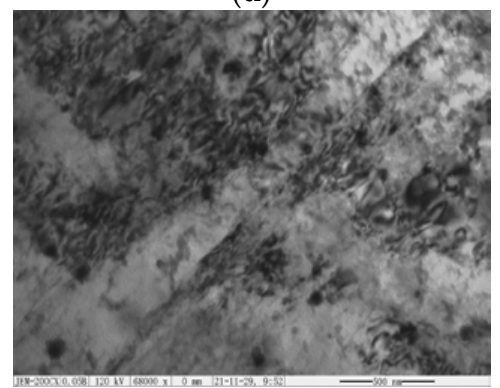

(f)

Figure 6. TEM images of as-compressed ZM6 alloy with single or two-step aging: (a) $250{ }^{\circ} \mathrm{C} \times 8.25 \mathrm{~h} ;(\mathbf{b}) 275^{\circ} \mathrm{C} \times 8.25 \mathrm{~h}$; (c) $300{ }^{\circ} \mathrm{C} \times 8.25 \mathrm{~h}$; (d) $275^{\circ} \mathrm{C} \times 0.15 \mathrm{~h}+200^{\circ} \mathrm{C} \times 8 \mathrm{~h}$; (e) $275^{\circ} \mathrm{C} \times 0.20 \mathrm{~h}+200^{\circ} \mathrm{C} \times 8 \mathrm{~h}$; (f) $300{ }^{\circ} \mathrm{C} \times 0.25 \mathrm{~h}+200^{\circ} \mathrm{C} \times 8 \mathrm{~h}$.

From Figure 6a, it can be seen that the $\beta^{\prime \prime}\left(\mathrm{Mg}_{3} \mathrm{Nd}\right)$ phase is uniformly distributed in the $\alpha-\mathrm{Mg}$ matrix, but its size is relatively uneven. From Figure $6 \mathrm{~b}$, the black flake $\beta$ " phase that is larger in size is completely coherent with the matrix, and its length is about $25 \mathrm{~nm}$. Figure $6 c$ shows cluster-like precipitates with uneven distribution. The precipitates are rodshaped and are 100-1500 $\mathrm{nm}$ in length, and a thin-layered (about $400 \mathrm{~nm}$ ) precipitation-free zone is formed near the grain boundary. The intersecting lamellae are dense point-like phases that are accumulated from the edges. As seen in Figure $6 \mathrm{~d}$, after pre-aging at $275^{\circ} \mathrm{C}$ for $0.15 \mathrm{~h}$, a large number of G.P. zones are formed in the $\alpha-\mathrm{Mg}$ matrix. Figure $6 \mathrm{c}$ shows two typical dislocations, and a dislocation network can be observed as a characteristic subgrain boundary that is formed by the interaction of those dislocations. Figure $6 \mathrm{~d}$ is a regularly arranged dislocation wall in which the same number of dislocations repel each other. Figure 6e shows the distribution of the $\beta^{\prime \prime}$ phase in the matrix after the $275^{\circ} \mathrm{C} \times 0.20 \mathrm{~h}$ $+200{ }^{\circ} \mathrm{C} \times 8 \mathrm{~h}$ aging treatments. The distribution of the $\beta^{\prime \prime}$ phase in the $\alpha-\mathrm{Mg}$ matrix is more dispersed than the one that formed as a result of treatment with the T6_SSAT process. Figure $6 \mathrm{f}$ demonstrates that the $\beta^{\prime \prime}$ phase has a length of about $10 \mathrm{~nm}$ and a thickness $2 \mathrm{~nm}$ after the TSAT process. Compared to the SSAT process, the $\beta^{\prime \prime}$ phase becomes smaller after the TSAT process.

\subsubsection{EDS and Phase Analysis after Aging Treatments}

The SEM-EDS analysis of the as-compressed ZM6 after the aging process is shown in Figure 7. 


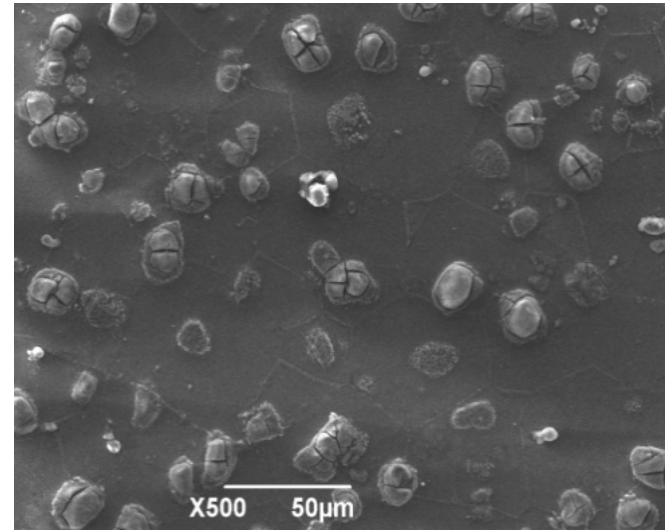

(a)

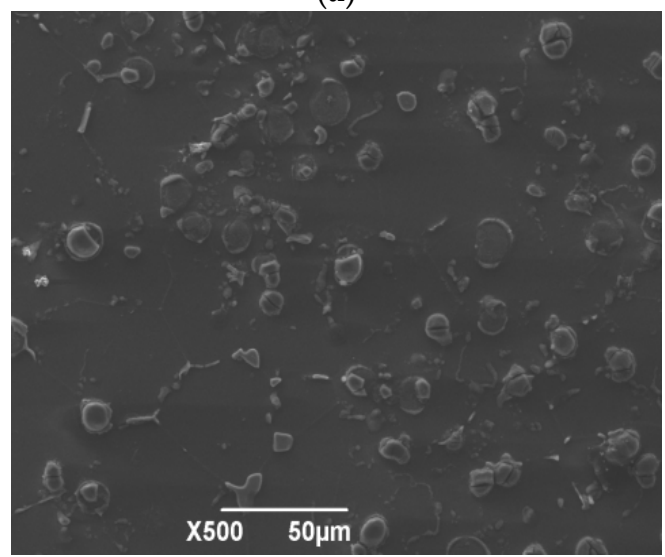

(c)

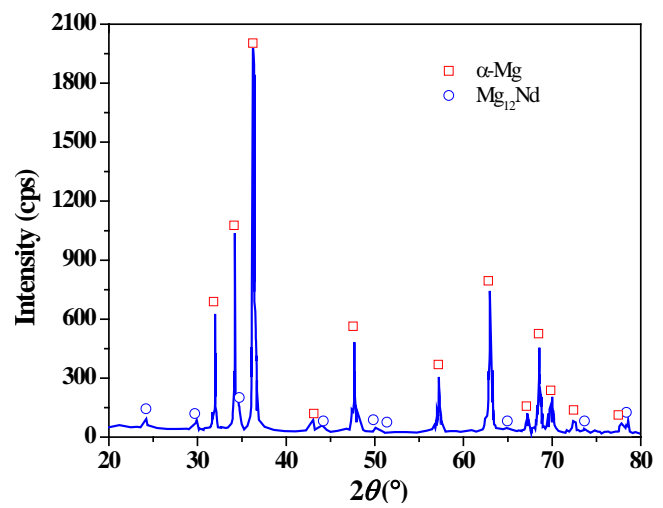

(e)

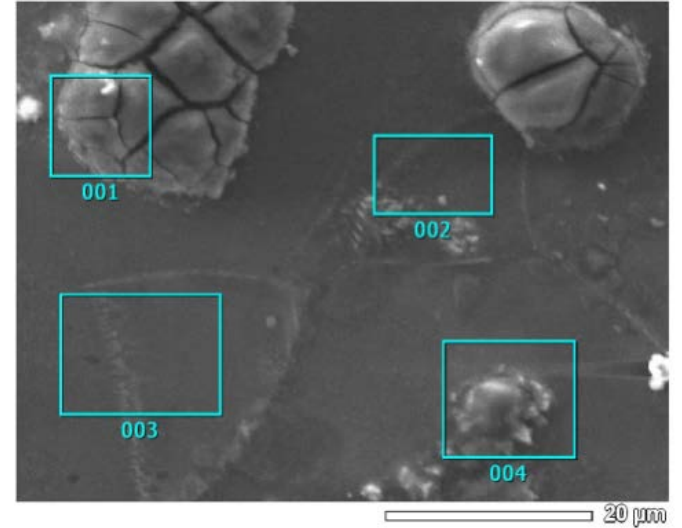

(b)

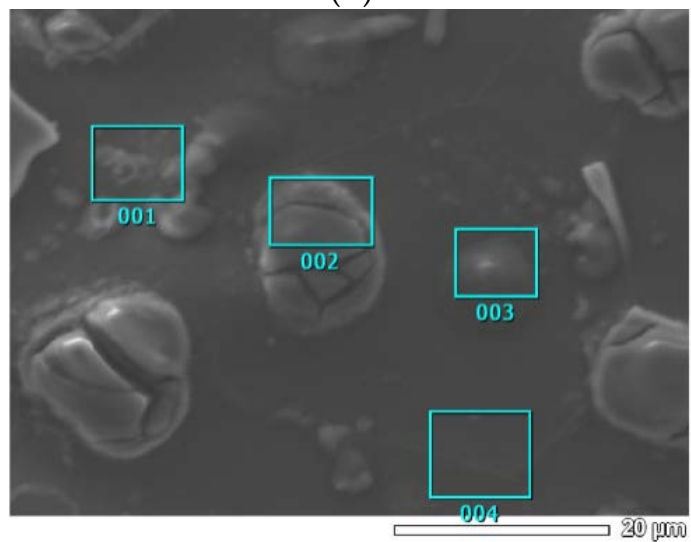

(d)

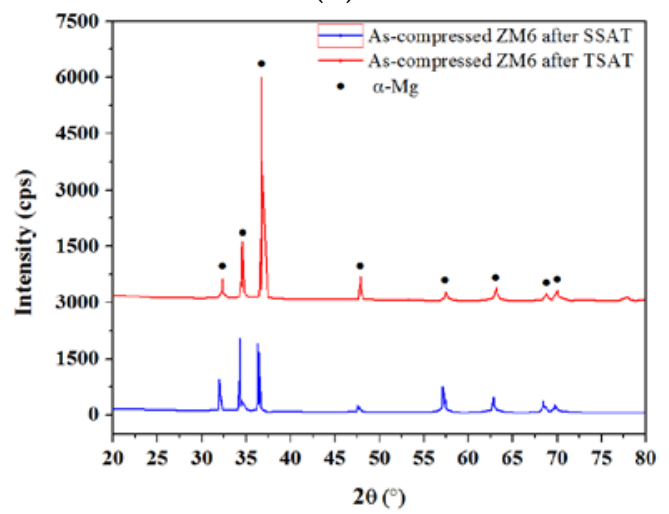

(f)

Figure 7. SEM-EDS and XRD analysis of as-compressed ZM6 alloy in discontinuous precipitated phases after aging process: (a) microstructure after the SSAT process; (b) EDS of sample after the SSAT process; (c) microstructure after TSAT process; (d) EDS of sample after the TSAT process; (e) XRD of sample after the TAST process; (f) XRD of sample after the SSAT and TSAT processes.

As seen in Figure 7a, the microstructure is composed of two parts: the gray portion is the $\alpha-\mathrm{Mg}$ matrix, that is, the solid solution $\mathrm{Zn}, \mathrm{Nd}$, and other elements in the $\alpha-\mathrm{Mg}$ matrix, and the grain is primary spherulite, which is present in a small amount in the eutectic phase and has an island-like distribution at the grain boundary [19]. The divorced eutectic $\alpha-\mathrm{Mg}$ phase is dependent on the $\alpha-\mathrm{Mg}$ growth that takes place during the primary phases. Meanwhile, the $\beta$ phase $\left(\mathrm{Mg}_{12} \mathrm{Nd}\right)$ and the $\mathrm{Zr}$-containing particles $\left(\mathrm{Zn}_{2} \mathrm{Zr}_{3}\right)$ exist alone at the grain boundary [20]. From Figure $7 b, c$, after the pre-aging process, the precipitation phase has a coherent relationship with the matrix, and then the secondary aging phase increases and becomes semi-coherent with the matrix. Figure 7e shows that the as-compressed ZM6 is composed of the $\alpha-\mathrm{Mg}$ matrix and $\mathrm{Mg}_{12} \mathrm{Nd}$ phase. In XRD pattern in 
magnesium alloys, the $\alpha$-mg Matrix has a dense hexagonal structure, with the precipitation of different rare earth phases and alloy phases, thus the matrix of the magnesium alloys can be strengthened [21-25]. From Figure 7f, the peak that is obtained by the TSAT process is higher than that that was obtained by the SSAT process, and the time that was needed to reach the peak was shorter due to the fact that there was a higher density of G.P. zones and a higher dispersion after the TSSAT process.

The EDS analysis in Figure 7 after the SSAT and TSAT processes is listed in Table 3.

Table 3. EDS spot analysis of ZM6 alloys after single-stage aging and two-stage aging processes.

\begin{tabular}{|c|c|c|c|c|c|c|c|c|c|c|c|c|}
\hline Element & $\begin{array}{c}\text { Spot } \\
\text { Position }\end{array}$ & Mass \% & Atom \% & $\begin{array}{c}\text { Spot } \\
\text { Position }\end{array}$ & Mass \% & Atom \% & $\begin{array}{c}\text { Spot } \\
\text { Position }\end{array}$ & Mass \% & Atom \% & $\begin{array}{c}\text { Spot } \\
\text { Position }\end{array}$ & Mass \% & Atom \% \\
\hline $\mathrm{Mg} \mathrm{K}$ & & 60.46 & 88.26 & & 83.72 & 96.64 & & 75.75 & 93.71 & & 81.70 & 95.70 \\
\hline Nd L & Spot 1 in & 32.28 & 7.94 & Spot 3 in & 15.06 & 2.93 & Spot 1 in & 19.14 & 3.99 & Spot 3 in & 15.15 & 2.99 \\
\hline $\mathrm{Zn} \mathrm{K}$ & Figure $8 a$ & 6.34 & 3.44 & Figure $8 \mathrm{a}$ & 0.47 & 0.20 & Figure $8 \mathrm{~b}$ & 4.74 & 2.18 & Figure $8 \mathrm{~b}$ & 2.64 & 1.15 \\
\hline $\mathrm{Zr} \mathrm{L}$ & & 0.92 & 0.36 & & 0.75 & 0.23 & & 0.36 & 0.12 & & 0.51 & 0.16 \\
\hline $\mathrm{Mg} \mathrm{K}$ & & 78.24 & 94.27 & & 79.65 & 94.82 & & 60.67 & 88.15 & & 85.98 & 96.98 \\
\hline Nd L & Spot 2 in & 16.06 & 3.26 & Spot 4 in & 14.90 & 2.99 & Spot 2 in & 31.17 & 7.63 & Spot 4 in & 12.21 & 2.32 \\
\hline $\mathrm{Zn} \mathrm{K}$ & Figure $8 a$ & 5.05 & 2.26 & Figure 8a & 3.68 & 1.63 & Figure $8 b$ & 6.95 & 3.75 & Figure $8 b$ & 1.31 & 0.55 \\
\hline $\mathrm{Zr} \mathrm{L}$ & & 0.65 & 0.21 & & 1.77 & 0.56 & & 1.21 & 0.47 & & 0.50 & 0.15 \\
\hline
\end{tabular}

As per the ESD analysis in Table 3, the second phase under the T6 condition is mainly a fine and dispersed â" phase $[26,27]$ when the peak hardness of the aging state is reached. $\mathrm{Zr}$ is used as a grain refiner in the ZM6 alloy, and the elements $\mathrm{Zn}, \mathrm{Nd}, \mathrm{Zr}$, and $\mathrm{Mg}$ are present at the spot positions of the smaller particles.

In order to further analyze the phase precipitates, the TEM, XRD, and EDS for the phase analysis before and after the two-stage aging process are shown in Figure 8.

Figure 7a shows the TEM image and EDS energy spectrum of the grain boundary precipitates. The precipitates are combined with the matrix, and the precipitates are massive, ranging from about $200-300 \mathrm{~nm}$ in size, and the grain size varies greatly, with some subcrystals appearing. In addition to the second phase at the grain boundary, a small number of lamellar and granular phases were found in the inner (IC) and grain boundary precipitates (GBP). Most of the lamellar phase is suspended in the crystal. There are two types of granular phases that are present in Figure 7a: one is a disorderly distribution in and around the grain boundary, where the size is less than $200 \mathrm{~nm}$, and the other is a directional arrangement along or near the grain boundary in the G.P. zones and is needle-shaped. The grain boundary precipitate phase exists between the intracrystalline precipitates during the two-stage aging process. A flaky phase, spotted-state phase, and half-elliptical phase also exist. The pre-deformed specimen consists of not only the $\beta^{\prime \prime} / \beta^{\prime}$ precipitates that are distributed, it also includes the globular or rod-shaped $\beta_{1}$ (FCC) precipitates on the dislocations in the matrix [8]. From Figure 7b, after pre-aging appears, the G.P. zones are totally coherent with the matrix, and these G.P. zones present as a heterogeneous core demonstrated limited distribution of the precipitated phase after the secondary aging process. It is generally believed that $\alpha-\mathrm{Zr}$ and $\mathrm{Mg}$ have the same h.c.p lattice structure. The $\mathrm{Zn}_{2} \mathrm{Zr}_{3}$ phase that precipitated in the solid solution process did not undergo any obvious changes during the aging process [20]. The EDS results show that the atomic ratios of $\mathrm{Mg}$, $\mathrm{Zn}$, and $\mathrm{Zr}$ are $54.18 \%, 18.51 \%$, and $27.31 \%$, respectively.

Figure $7 \mathrm{c}$ shows the semi-elliptical precipitates that are found in the grain boundaries. The energy spectra of the flaky phase, granular phase, and semi-elliptic precipitated phase are similar and are demonstrated to be composed of $\mathrm{Mg}$ and $\mathrm{Nd}$ and to belong to different forms of the same substance. The precipitated $\mathrm{Mg}_{12} \mathrm{Nd}$ phase in the as-compressed microstructure has three forms: the bulk phase in the grain boundary, the flake phase in the grain boundary, and the granular phase near the grain boundary. Figure 7c shows the intragranular electron diffraction pattern of the selected area. The bright large spots in the calibration diagram are the diffraction patterns of the $\alpha-\mathrm{Mg}$ matrix [21-25], while the small spots in the $1 / 2$ matrix are those of $\mathrm{Mg}_{12} \mathrm{Nd}$ and demonstrate somewhat of a coherent relationship with the $\alpha-\mathrm{Mg}$ matrix. Figure $7 \mathrm{~d}$ shows the precipitation phase of $\mathrm{Mg}_{12} \mathrm{Nd}$ at the grain boundary. There are obvious precipitates at the grain boundary, 
linear precipitates near the grain boundary, and spherical precipitates with a diameter of $1-2 \mu \mathrm{m}$ that are distributed in the crystal. The precipitates that are at the grain boundary are in either the $\mathrm{Mg}_{9} \mathrm{Nd}$ or $\mathrm{Mg}_{12}(\mathrm{Nd}, \mathrm{Zn})$ phase $[19,20]$. These particles are supposed to be $\mathrm{Mg}_{12} \mathrm{Nd}$, and the smaller particles are arranged in a linear fashion around dislocations or grain boundaries [28,29].
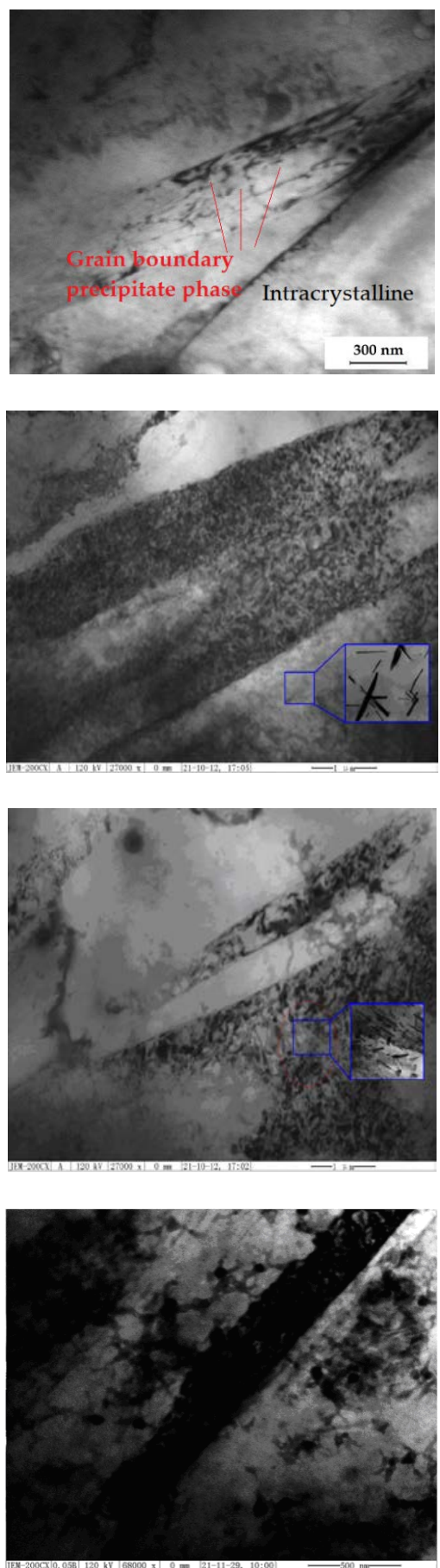

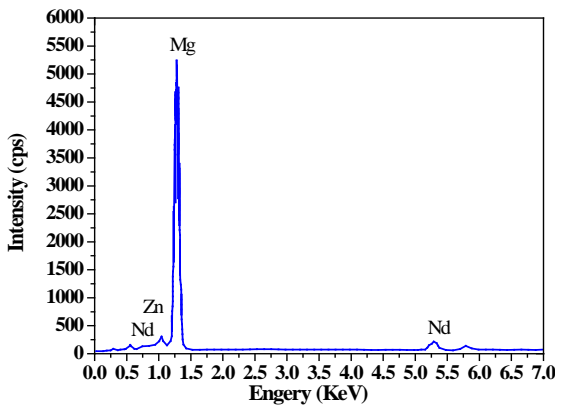

(a)

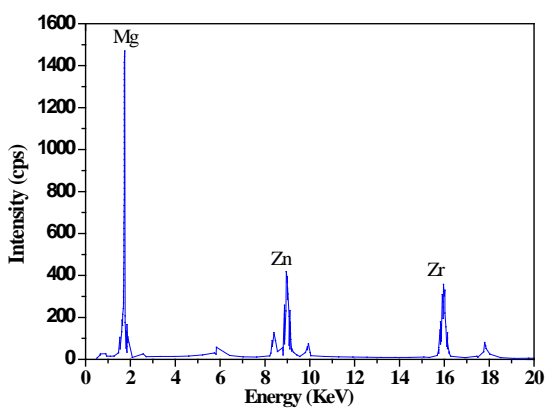

(b)

(c)
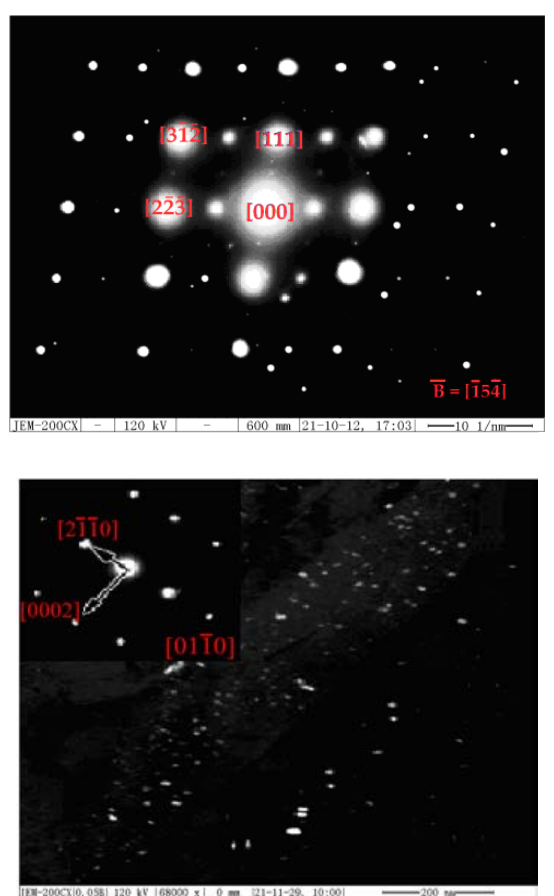

(d)

Figure 8. Phase analysis of as-compressed ZM6 before and after the two-stage aging process: (a) Grain boundary precipitate and EDS analysis after the TAST process; (b) TEM and EDS of continuously precipitated $\mathrm{Zn}_{2} \mathrm{Zr}_{3}$ phase after the TAST process; (c) TEM of the grainy precipitated phase and selected area diffraction patterns of spotted state precipitated $\mathrm{Mg}_{12} \mathrm{Nd}$ phase after the TAST process; (d) TEM bright-field image and TEM dark-field images of precipitates after the TAST process. 


\subsubsection{Precipitation Mechanism and Strengthening Mechanism}

After the two-stage aging process, the tensile surface fracture at ambient temperature was determined and is shown in Figure 9.

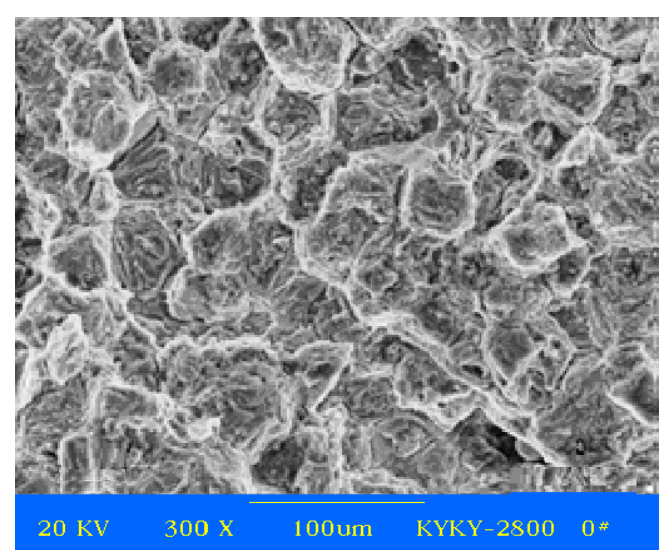

(a)

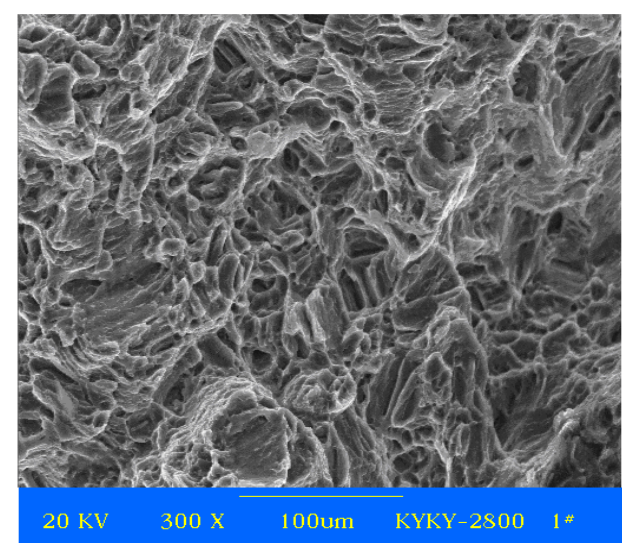

(b)

Figure 9. Tensile surface fracture of ZM6 after the two-stage aging process: (a) as-cast state; (b) as-compressed state.

Figure 9a shows that the as-cast ZM6 alloy has more obvious ductile fracture characteristics with an obvious tearing line and with spherical particles in the dimples. Moreover, the tensile deformation mechanism of the precipitation phase is mainly conducted by slip and twinning, and the dislocations are shown to demonstrate a continuous flow along the slip surface. Figure 9a shows how cleavage fractures and torn edges appeared; the intergranular fracture is the main mode and is partly along the mixed transgranular. In Figure 9b, the macroscopic fracture of the as-compressed ZM6 alloy is flush, and the granular fracture is depicted with a darker color. As the deformation of the magnesium alloy is not coordinated, and the crack source is easy to produce in the precipitation phase [30,31], which leads to a decrease in the elongation. In the durable fracture that is caused by aging in Figure $9 \mathrm{~b}$, there are many cracks in the grain boundary, and the grain boundary crack is more obvious. Although the tensile fracture surface is ductile, $\mathrm{Mg}(\mathrm{Zn}) \mathrm{Zr}$ compound particles still exist in the deep part of the dimples. In fact, the dislocation slip and deformation twins of wrought magnesium alloys often interact [32,33], which has an important effect on mechanical properties

The precipitation formation mechanism that takes place during the aging process is shown in Figure 10.

Figure 10a shows the schematic diagram of the precipitate transformation mechanism in a single-stage aging process. Generally, the existence of a G.P. zone ranges from room temperature to $180{ }^{\circ} \mathrm{C}$, â" ranges from $180{ }^{\circ} \mathrm{C}$ to $260{ }^{\circ} \mathrm{C}$, and $\hat{a}^{\prime}$ ranges from $200{ }^{\circ} \mathrm{C}$ to $320^{\circ} \mathrm{C}$. Meanwhile, â exists at a higher temperature range, from $300{ }^{\circ} \mathrm{C}$ to the solvus temperature of about $550{ }^{\circ} \mathrm{C}[31,32]$. The precipitation order is found to be [31-33]: supersaturated solution $\rightarrow$ G.P. zones $\rightarrow \alpha($ hcp $) \rightarrow \beta^{\prime \prime}\left(\mathrm{D}_{19}\right) \rightarrow \beta^{\prime}(\mathrm{fcc}) \rightarrow \beta(\mathrm{bct})$, and the grainy precipitate is varied: the phaseflaky phase, spotted state phase, and half-elliptical phase. The G.P. zones are needle shaped and are located along the (0001) direction, as shown in Figure 10b. When a single-stage aging treatment is applied at $200^{\circ} \mathrm{C}$ for $8 \mathrm{~h}$, heterogeneous $\beta^{\prime \prime}$ phases $[3,30]$ are rapidly precipitated from a supersaturated solid solution and grow rapidly due to the high aging temperature and due to early aging. However, in a certain range near the precipitates of the $\beta$ " phase in the early stage of aging, a dilution zone of solute atoms will be formed. As the aging time increases, the dilution zone will expand as the $\beta^{\prime \prime}$ phase continues to grow in the depleted zone of solute atom, making it difficult for the $\beta^{\prime \prime}$ phase to grow a nucleus during the later aging period. Therefore, after single-stage aging at $200{ }^{\circ} \mathrm{C}$ for $8.25 \mathrm{~h}$, the size and dispersion of the $\beta "$ phase are larger and lower. Figure 10c shows the schematic diagram of the phase transformation and precipitation 
mechanism during the two-stage aging process. Compared to single-stage aging, the $\beta^{\prime \prime}$ phase density becomes larger, the size becomes smaller, and the $\beta^{\prime \prime}$ phase distribution is more dispersed [34-36]. During the pre-aging process, a large number of dispersed G.P. zones are first formed in the matrix. During the two-stage aging process, heterogeneous nuclei from the $\beta$ " phase in the G.P. zones increase and form a large number of dispersed $\beta^{\prime \prime}$ phases. As the heterogeneous nucleus of the $\hat{a}^{\prime \prime}\left(\mathrm{Mg}_{3} \mathrm{Nd}\right)$ phase and the $\hat{a}^{\prime \prime}$ region increase, a large number of dispersed â $\left(\mathrm{Mg}_{12} \mathrm{Nd}\right)$ phases are formed [8]. According to references [17-19], the $\hat{a}^{\prime \prime}$ and $\hat{a}^{\prime}$ phases are both plate-shaped and tend to be $\{11 \overline{2} 0\}$ and $\{10 \overline{1} 0\}$. The â' phase (probably $\mathrm{Mg}_{9} \mathrm{Nd}$ or $\mathrm{Mg}_{41} \mathrm{Nd}_{5}$ ) demonstrates nucleates with a hexagonal structure on the dislocations [19] and demonstrate an apparent parallel orientation at $(11 \overline{2} 0)_{\beta \prime} \|(10 \overline{1} 0)_{M g}$ and $(\overline{1} 014)_{\beta \prime} \|(0001)_{M g}$. The â" $\left(\mathrm{Mg}_{3} \mathrm{Nd}, a=0.64 \mathrm{~nm}, c=0.52 \mathrm{~nm}\right)$ is perfectly coherent with the $\mathrm{D} 0_{19}$ superlattice, that is, $a_{\beta^{\prime \prime}}=a_{M g}, c_{\beta^{\prime \prime}}=c_{M g}, a_{\beta^{\prime \prime}} \| a_{M g}$, and $c_{\beta^{\prime \prime}} \| c_{M g}[8,18]$. The â $\left(\mathrm{Mg}_{12} \mathrm{Nd}\right)$ particles are incoherent and demonstrate a body-centred tetragonal symmetry of $a=1.031 \mathrm{~nm}, c=0.593 \mathrm{~nm}$ [19], as shown in Figure 10d.

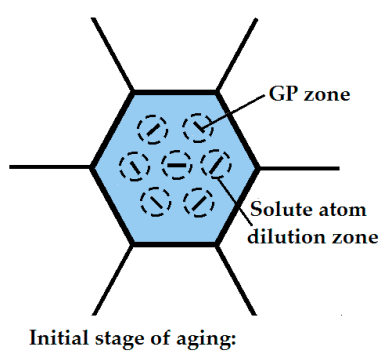

Growth of phase nucleus

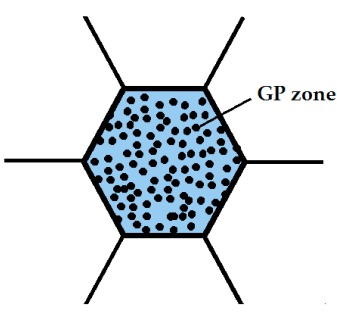

Initial stage of aging: Lots of scattered GP zones formed

(a)
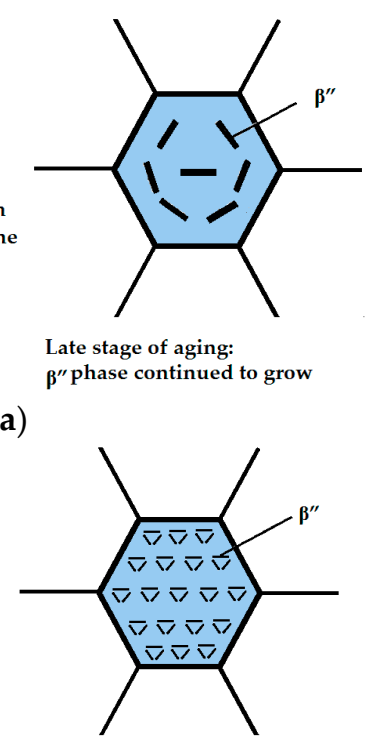

Late stage of aging:

GP region transformed into dispersed $\beta$ " phase

(c)
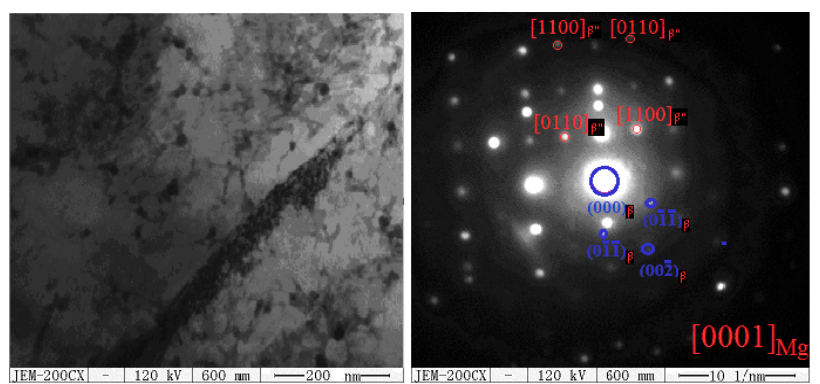

(b)

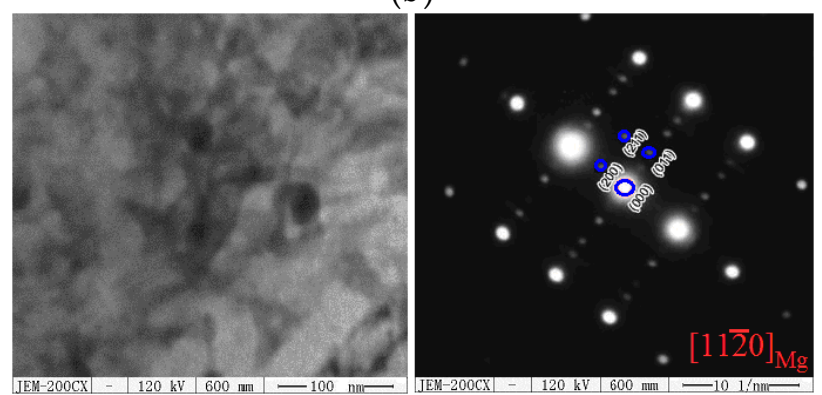

(d)

Figure 10. Precipitation formation mechanism by the SSAT and TSAT processes: (a) initial and final stages of the SSAT process; (b) TEM and SAED patterns of precipitates parallel to the (0001) $)_{\mathrm{Mg}}$ zone axe by the SSAT process; (c) initial and final stages of pre-aging by the TSAT process; (d) TEM and SAED patterns parallel to (1120) $)_{\mathrm{Mg}}$ by the TSAT process.

\subsection{Experimental Tensile Properties under Various Heat Treatments}

3.3.1. Effect of Aging Temperature on Tensile Properties of As-Cast and As-Compressed ZM6

After the solid solution process $\left(525^{\circ} \mathrm{C} \times 4 \mathrm{~h}\right)$, for the T6_SAST process, the aging temperature region was $100-400^{\circ} \mathrm{C}$, and the aging time was $8.25 \mathrm{~h}$. Moreover, for the T6_TAST process, the pre-aging temperature region is between $225^{\circ} \mathrm{C}$ and $300{ }^{\circ} \mathrm{C}$, the pre-aging time is $12.0 \mathrm{~min}$, and the final aging is at $200{ }^{\circ} \mathrm{C}$ for $8 \mathrm{~h}$. The measured mechanical properties as well as the grain size under various aging temperatures are shown in Figure 11.

In Figure 11, the ultimate tensile stress (UTS) and yield stress are shown to decrease as the aging temperature increases. As the pre-aging temperature increases, the hardness at room temperature first increases and then decreases after the final aging process. When the aging time is extended, the overall strength during high-temperature tensile deformation gradually increases to its maximum value and then rapidly declines. For an aging process that takes place after the solution process, when the aging temperature increases, the 
microstructure demonstrates no significant difference, and the aging temperature has little effect on the grain size. The higher the aging temperature, the shorter the supersaturation of the solid solution and the shorter the time to reach the strength peak are. The lower the aging temperatures of the as-cast and as-compressed ZM6 alloys are, the higher the maximum hardness is. As the pre-aging temperature increases, the diffusion rate of alloying elements accelerates, and the phase is rapidly separated, so the required time is shorter. The mechanical properties of the both as-cast and as-compressed ZM6 alloys are very good at $200{ }^{\circ} \mathrm{C}$, with an average relative fine grain size about $40 \mu \mathrm{m}$ and $25 \mu \mathrm{m}$. In particular, there is a very good instantaneous tensile yield at $275{ }^{\circ} \mathrm{C}$ during the two-stage aging process.

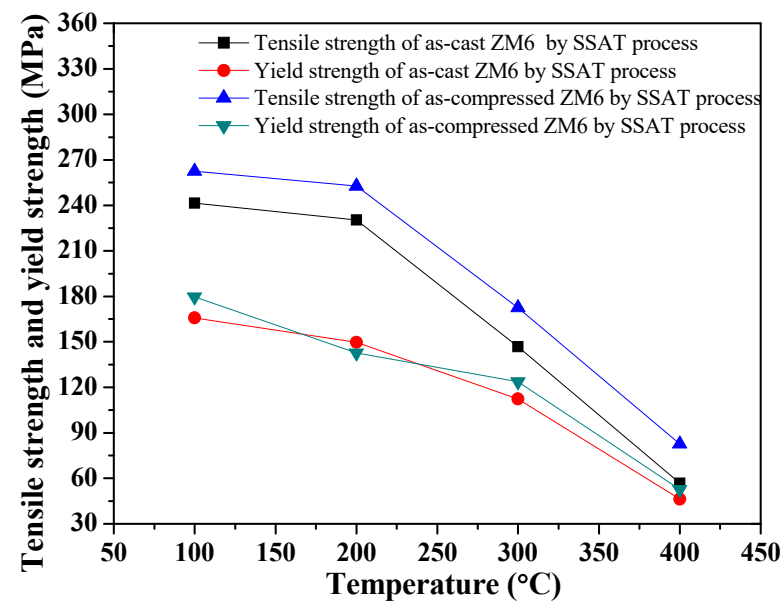

(a)

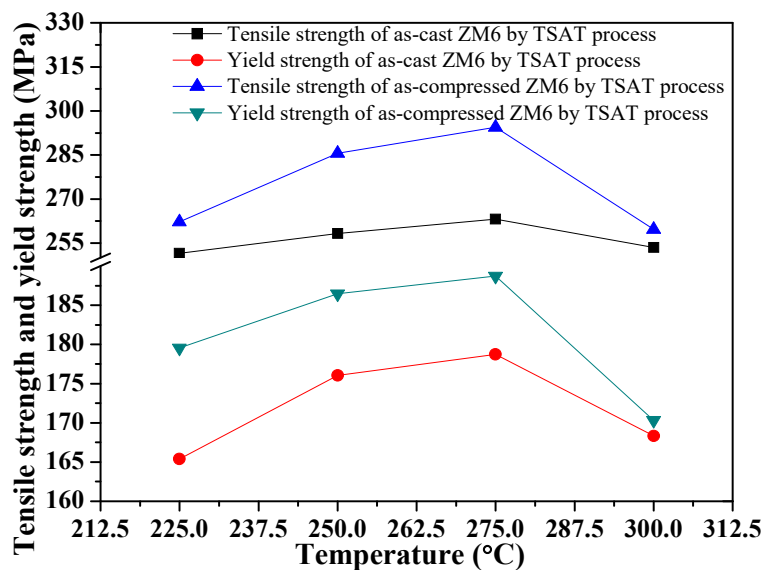

(c)

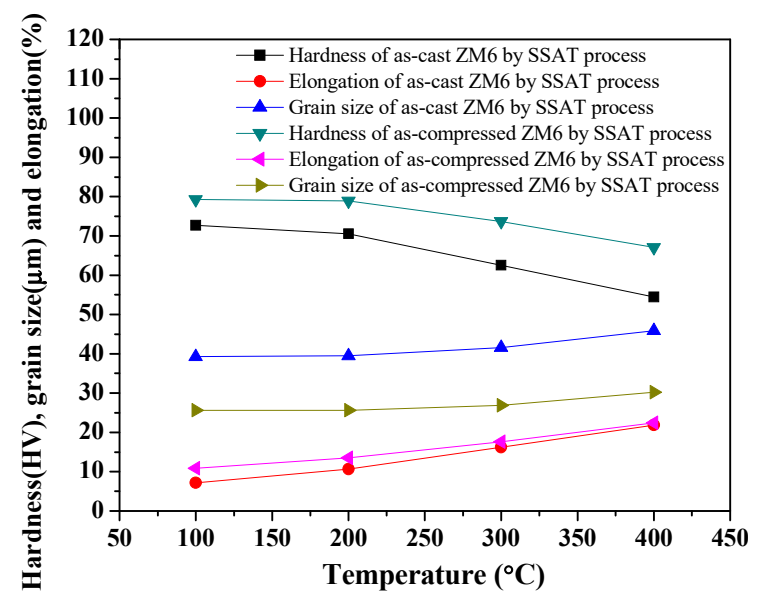

(b)

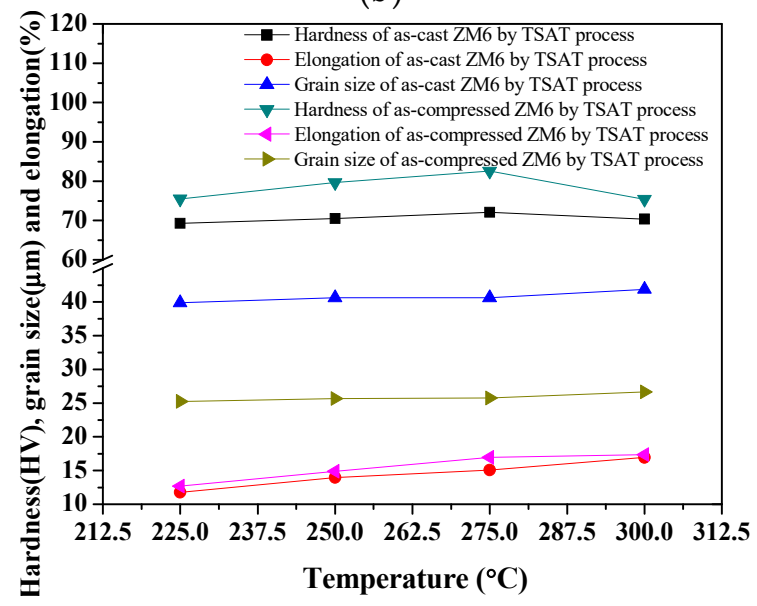

(d)

Figure 11. Mechanical properties and grain size of ZM6 alloys under various aging temperatures: (a) tensile and yield strength by SAST process; (b) hardness, elongation, and grain size by SAST process; (c) tensile and yield strength by TAST process; (d) hardness, elongation, and grain size by TAST process.

\subsubsection{Effect of Aging Time on Tensile Properties of As-Cast and As-Compressed ZM6}

After the solid solution process $\left(525^{\circ} \mathrm{C} \times 4 \mathrm{~h}\right)$, for the T6_SAST process, the aging temperature region was $275^{\circ} \mathrm{C}$, and the aging time was between $8 \mathrm{~h}$ and $20 \mathrm{~h}$. Moreover, for the T6_TAST process, the regulation of the pre-aging temperature region was $275{ }^{\circ} \mathrm{C}$, the pre-aging time was $6.0-15.0 \mathrm{~min}$, and the final aging temperature was at $200{ }^{\circ} \mathrm{C}$ with a holding time of $8.0 \mathrm{~h}$. The effects of the aging time on the mechanical properties that were affected by the aging process are shown in Figure 12.

After solution treatment, the length of time that was required for the subsequent aging process had an important effect on mechanical properties. From Figure 12a,b, the mechanical properties that were achieved by the T6_SSAT process reached their peak values 
after $16 \mathrm{~h}$ of aging, demonstrating a tensile strength of $230.32 \mathrm{MPa}$, a yield strength of $149.65 \mathrm{MPa}$, and hardness of $70.5 \mathrm{HV}$. For the T6_SSAT process, the highest tensile strength appears at the pre-aging time of $12 \mathrm{~min}$, where $\sigma_{\mathrm{b}}=294.46 \mathrm{MPa}, \sigma_{0.2}=188.72 \mathrm{MPa}$, and $\delta=10.93 \%$. When the aging time exceeds $16 \mathrm{~h}$, the tensile strength decreases, elongation increases, and over-aging occurs. During the aging process, the changes in the precipitation phase directly affect the changes that take place in the mechanical properties of the alloy. When the alloy is aged, the strength is increased, and the plasticity is decreased due to the precipitation of the $\hat{a}^{\prime \prime}\left(\mathrm{Mg}_{3} \mathrm{Nd}\right)$ and $\hat{a}\left(\mathrm{Mg}_{12} \mathrm{Nd}\right)$ phases [37-39]. When the aging time is $16 \mathrm{~h}$, the UTS reaches $294.46 \mathrm{MPa}$, and the elongation decreases to $10.93 \%$. From Figure $12 \mathrm{c}, \mathrm{d}$, as the pre-aging time increases, the strength and hardness increase first and then decrease after the final aging period, and reach their maximum values at $275^{\circ} \mathrm{C}$, where the effect of pre-aging at $275^{\circ} \mathrm{C}$ for $10 \mathrm{~min}$ is the best. For the two-stage aging process at $525{ }^{\circ} \mathrm{C} \times 4 \mathrm{~h}+275^{\circ} \mathrm{C} \times 12 \mathrm{~min}+200^{\circ} \mathrm{C} \times 8 \mathrm{~h}$, the comprehensive mechanical properties of the as-compressed ZM6 alloy are the best, demonstrating a yield strength of 188.72 MPa, a tensile strength of $294.46 \mathrm{MPa}$, and a hardness of $82.56 \mathrm{HV}$ compared to the single-stage aging process. There is a very good short-term (12 $\mathrm{min}$ ) aging limit between $250^{\circ} \mathrm{C}$ and $325^{\circ} \mathrm{C}$.

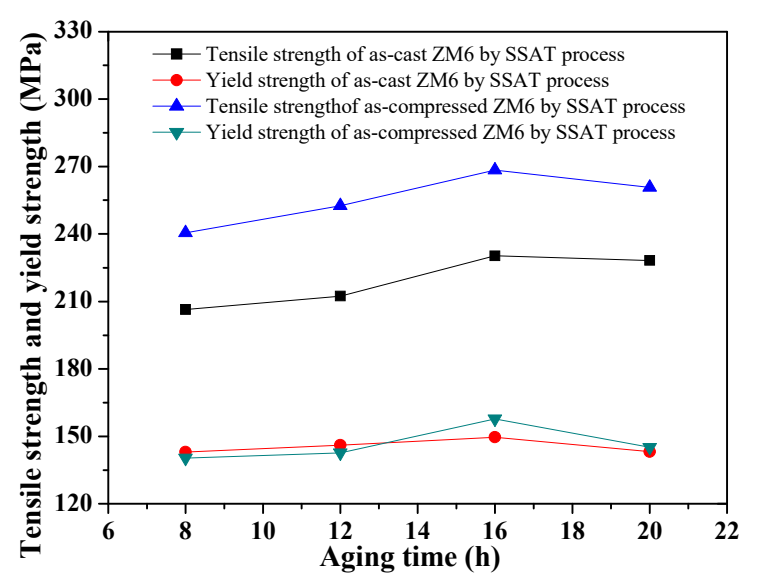

(a)

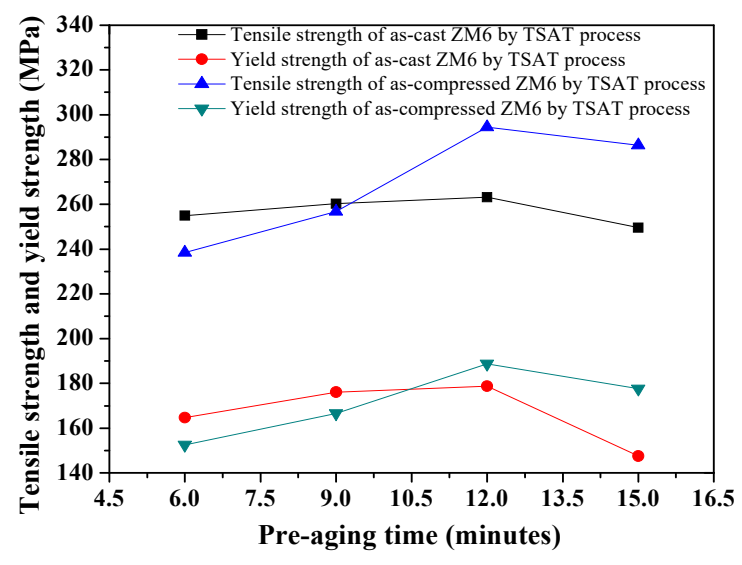

(c)

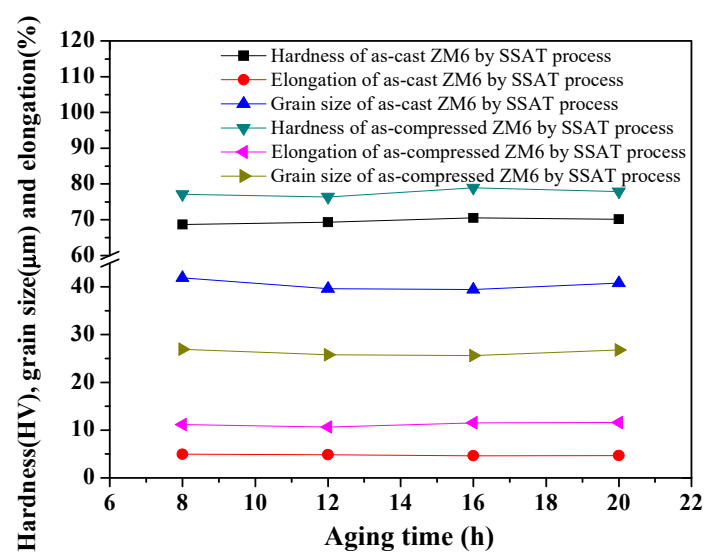

(b)

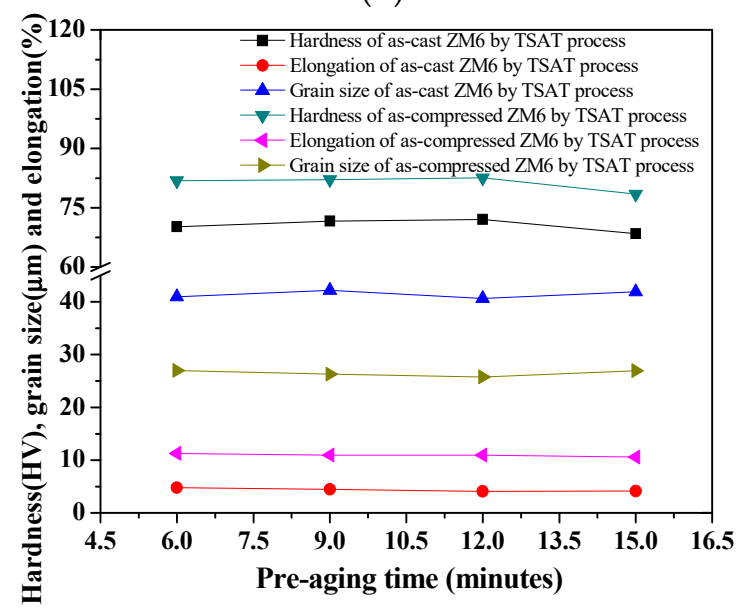

(d)

Figure 12. Mechanical properties and grain size of ZM6 alloys under various aging times: (a) tensile and yield strength by SAST process; (b) hardness, elongation, and grain size by SAST process; (c) tensile and yield strength by TAST process; (d) Hardness, elongation, and grain size by TAST process.

The comparative mechanical properties of the as-compressed ZM6 alloy that were achieved by the T5 and T6_SAST processes are shown in Figure 13. 


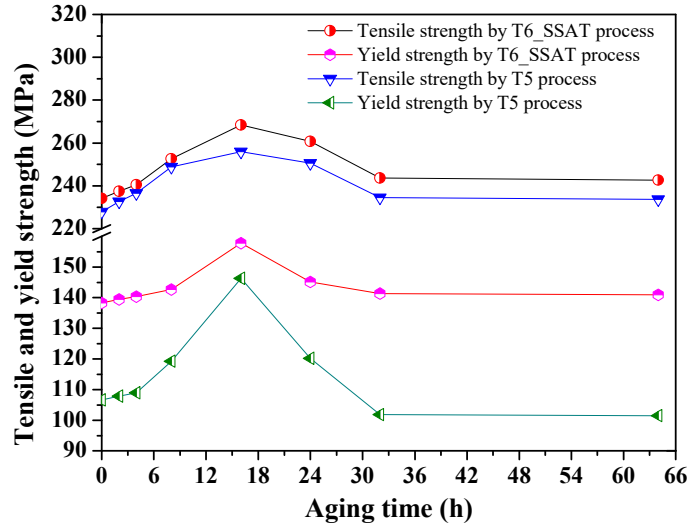

(a)

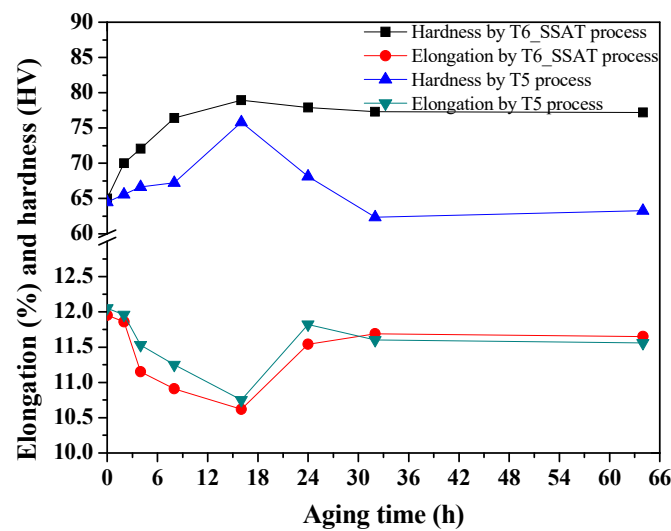

(b)

Figure 13. Comparative mechanical properties of as-compressed ZM6 alloy by T5 and T6_SAST processes: (a) tensile and yield strength; (b) elongation and hardness.

From Figure 13a, the strength increases gradually and then decreases slightly as the aging time increases. After solution treatment and aging for $16 \mathrm{~h}$, the strength of the as-compressed ZM6 alloy reached its highest value of $268.84 \mathrm{MPa}$ when the aging time was $16 \mathrm{~h}$, and the elongation of the alloy also drops to the lowest point, but the elongation of $11.54 \%$ is still higher than that of the as-cast alloy. From Figure 13b, when the aging time was $16 \mathrm{~h}$ by T6_TSAT process, the elongation decreased from $11.95 \%$ to $10.62 \%$. After aging for $16 \mathrm{~h}$, during the longer aging time, the mechanical properties of the alloy did not change much. When the aging time for T6_TSAT the process is prolonged from $16 \mathrm{~h}$ to $64 \mathrm{~h}$, the strength only changes by $3.1 \mathrm{MPa}$, and the elongation decreases by $0.5 \%$. From Figure 13 , the strength of the as-compressed ZM6 alloy by the T5 and T6_SAST processes increased along with the aging time, but the elongation of the alloy decreased gradually. The strength and hardness first increased and then decreased after the T5 treatment. During the whole aging process, the tensile strength and elongation changes showed opposite tendencies.

With the extension of the aging time, the precipitated phase at the boundary became thick and even. For the SSAT and TAST processes, when the dislocation bypassed the second phase particle, the yield stress was inversely proportional to the particle spacing, and the precipitation phase spacing was reduced.

\subsubsection{Comparison of Mechanical Properties under Various Heat Treatment Conditions}

Comparison of mechanical properties as well as grain size in the as-cast and ascompressed alloys under the T5 and T6 conditions are shown in Figure 14.

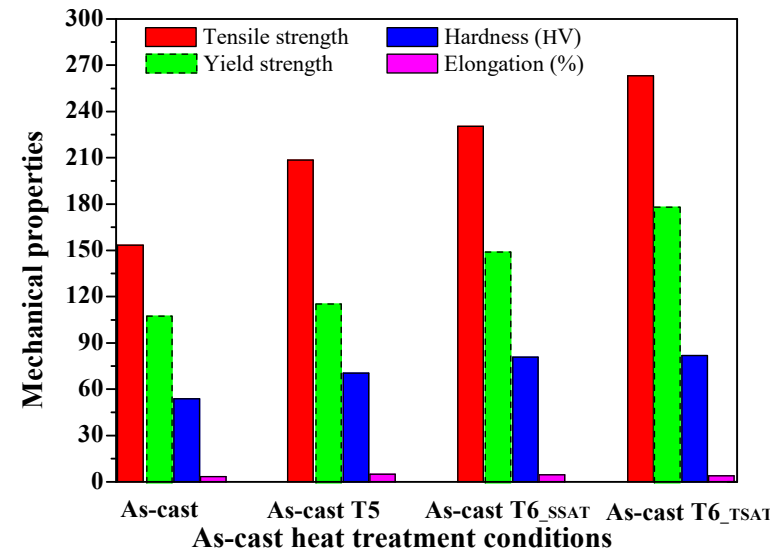

(a)

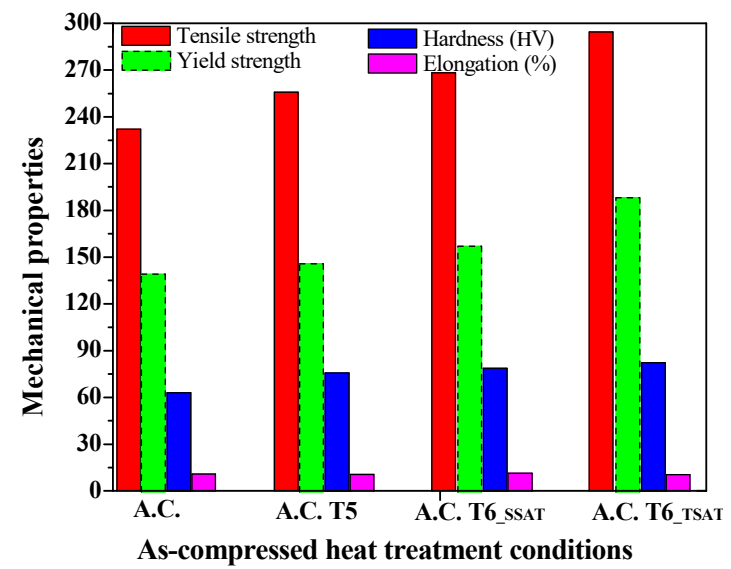

(b)

Figure 14. Mechanical properties of ZM6 alloys under different conditions: (a) mechanical properties under various as-cast treatment conditions; (b) mechanical properties under various as-compressed treatment conditions. 
Figure 14a shows the tensile strength at room temperature in different states. Figure 14 shows a comparison of the tensile properties between the as-cast state and the compression state. After the hot compression in Figure 14b, the strength is further increased because the microstructure is further refined and because the grain boundary per unit volume increases. During the tensile process, the non-complete microstructure homogeneity makes it difficult for the external load to be completely distributed and transferred to the neighboring grains, and these large grains become the source of the fracture, leading to the ductility decreasing. Under the same conditions, the mechanical properties of all of the compressed alloys are obviously better than those of the as-cast alloys. The reason for the differences in the mechanical properties is that more dispersed precipitates formed in the G.P. zones after secondary aging, thus strengthening the alloy $[40,41]$. Compared to the as-cast samples, the strength and elongation of the as-compressed ZM6 alloy increase. This is due to increases in both grain refinement and the grain boundaries, which can effectively prevent dislocation movement, resulting in increases in both the strength and elongation.

Mechanical properties, hardness, and the subsequent ZM6 heat-resistant magnesium alloy phases under different heat treatments are listed in Table 4.

Table 4. Comparison of tensile properties, hardness at room temperature, and strengthening mechanisms under various conditions.

\begin{tabular}{|c|c|c|c|c|c|}
\hline Condition & $\sigma_{\mathrm{b}}(\mathrm{MPa})$ & $\sigma_{0.2}(\mathrm{MPa})$ & $\delta(\%)$ & Hardness (HV) & $\begin{array}{l}\text { Strengthening } \\
\text { Mechanisms }\end{array}$ \\
\hline As-cast & 153.36 & 108.13 & 3.14 & 54.12 & M.S. + S.S.S. \\
\hline As-cast T6-SSAT & 230.32 & 149.65 & 4.63 & 70.50 & M.S. + S.S.S. + P.S. \\
\hline As-cast T6-TSAT & 263.16 & 178.75 & 4.07 & 72.05 & M.S. + S.S.S. + P.S. \\
\hline As-compressed & 232.16 & 139.75 & 10.67 & 63.26 & M.S. + F.G.S. \\
\hline As-compressed + T4 & 208.42 & 115.81 & 12.96 & 59.63 & M.S. + S.S.S. + F.G.S. \\
\hline As-compressed + T5 & 255.88 & 146.28 & 10.75 & 75.82 & M.S. + F.G.S. + P.S. \\
\hline As-compressed + T6_SSAT & 268.35 & 157.65 & 11.52 & 78.92 & M.S. + S.S.S. + F.G.S. + P.S. \\
\hline As-compressed + T6_TSAT & 294.46 & 188.72 & 10.93 & 82.56 & M.S. + S.S.S. + F.G.S.+ P.S. \\
\hline
\end{tabular}

As seen in Table 4, the ultimate tensile strength and the elongation of the as-cast ZM6 alloys are $155.36 \mathrm{MPa}$ and $3.14 \%$, respectively. After hot compression, the intermetallic compounds that broke down during the compression process also prevent the dislocation from moving, resulting in an increase in the tensile strength. For the as-compressed state, the $\sigma_{b}$ increased to $294.46 \mathrm{MPa}$, and the elongation $\delta$ increased from $3.14 \%$ to $10.93 \%$ compared to that of as-cast ZM6. The matrix is strengthened by the appearance of a new grain boundary; thus, the strength and ductility are largely improved through hot compression. The ductility of the as-compressed alloys was higher than that of those alloys that were in the as-cast state. The UTS value of the as-compressed alloys obviously decreased, and the elongation increased after T4 treatment. After T5 treatment, the UTS value of the as-compressed alloy increased slightly, and the elongation the at break decreased. The elongation that took place during two-stage aging is lower than the elongation that took place during single-stage aging, where the elongation decreased by $5.12 \%$ and the tensile strength increased by $9.73 \%$; thus, the heat treatment period is shortened. For the strengthening mechanisms, S.S.S. represents the solid solution strengthening, P.S. represents the precipitation strengthening, F.G.S. stands for the fine grain strengthening, and M.S. is the matrix strengthening. After the T4 solution aging treatment, a discontinued precipitated phase was produced at the grain boundary at the initial aging stage, and the elastic modulus of the matrix was therefore increased by solid solution strengthening (S.S.S.). After the TAST process, the precipitated-phase $\mathrm{Mg}_{12} \mathrm{Nd}$ with a BCT structure was linear or banded along the base plane of $(0001) \mathrm{Mg}$, and the density near the grain boundary was higher than that in the crystal. The particles with linear distribution had an obvious strengthening effect on the $\mathrm{Mg}$ matrix. Moreover, there is a large stress field at the coherent interface between the matrix á-Mg and the â phase, which hinders the dislocation movement. During the aging process, a large number of precipitated-phase $\mathrm{Mg}_{12} \mathrm{Nd}$ particles precipitated from a matrix. The smaller 
size and higher dispersion of the â" phase were able to be obtained by decreasing the aging time within a certain temperature range [20], influencing the mechanical properties. The precipitation plays a pinning role for the dislocation and prevents the grain boundary from sliding, thus increasing the strength $[42,43]$. Therefore, after the two-stage aging treatment, the tensile strength is obviously improved, and there are slight changes in the elongation, which not only improves the mechanical properties but also reduces the heat treatment time.

In all, by studying the effect of the TSAT process on the microstructure and properties of ZM6 alloy, the aging time can be shortened effectively, allowing better properties to be obtained and better quality control of ZM6 products to be achieved.

\section{Conclusions}

The different a $\mathrm{ZM} 6\left(\mathrm{Mg}_{2.6} \mathrm{Nd}_{0.4} \mathrm{Zn}_{0.4} \mathrm{Zr}\right)$ aging processes were designed, and the phase precipitation and microstructure were analyzed after various heat treatments. Moreover, the mechanical properties that were achieved after various aging processes were discussed. The following results were obtained:

(1) As-cast ZM6 alloys consist of $\alpha-\mathrm{Mg}$ and $\mathrm{Mg}_{12} \mathrm{Nd}$ phases. The $\mathrm{Mg}_{12} \mathrm{Nd}$ phase is mainly distributed along the grain boundaries. $\mathrm{Mg}_{12} \mathrm{Nd}$ is distributed in the crystal and the grain boundary in the form of intersecting sheets, which are formed by the aggregation of the point-precipitated phases. The order of precipitation that occurs during the SSAT and TSAT processes was verified to be: supersaturated solution $\rightarrow$ G.P. zones $\rightarrow \alpha(\mathrm{hcp}) \rightarrow \beta^{\prime \prime}\left(\mathrm{D}_{19}\right) \rightarrow \beta^{\prime}(\mathrm{fcc}) \rightarrow \beta(\mathrm{bct})$.

(2) As-compressed ZM6 alloys formed an $\alpha$-Mg solid solution at $636.54{ }^{\circ} \mathrm{C}$, and when it was cooled to $586.90^{\circ} \mathrm{C}$, it produced a $\mathrm{Mg}_{12} \mathrm{Nd}$ phase until the end of the eutectic reaction at $567.91{ }^{\circ} \mathrm{C}$. There were no obvious differences in the microstructures of the as-cast and as-compressed ZM6 alloys; however, there was an obvious increase in the number of twins. Moreover, the twins that were inside and outside of the grain boundary were different in the as-compressed samples that did not undergo heat treatment.

(3) After pre-aging at $275^{\circ} \mathrm{C}$ for $12 \mathrm{~min}$, a large number of small and dispersed G.P. zones were formed in the $\alpha$-Mg matrix. After the two-stage aging treatment, the homogeneous lamellar $\mathrm{Mg}_{3} \mathrm{Nd}$ phase formed along the grain boundary, and the continuous precipitated fine $\mathrm{Mg}_{12} \mathrm{Nd}$ phase formed in the grains. During the second aging process at $200^{\circ} \mathrm{C}$ for $8 \mathrm{~h}$, the G.P. zone was used as the core of the $\beta$ " phase; thus, the size of the $\beta^{\prime \prime}$ phase was refined, and the density and dispersion of the $\beta$ phase were increased at the end of the process.

(4) When the pre-aging time increased, the elongation decreased slightly, and the tensile strength demonstrated an obvious increase. When the pre-aging process was at $275{ }^{\circ} \mathrm{C}$ for $12 \mathrm{~min}$ and when the secondary aging process was at $200{ }^{\circ} \mathrm{C}$ for $8 \mathrm{~h}$, the tensile strength reached $294.46 \mathrm{MPa}$, which was $26.11 \mathrm{MPa}$ higher than that obtained for the single-stage aging process at $200^{\circ} \mathrm{C}$ for $8.25 \mathrm{~h}$.

(5) Compared to the T6 treatment, the tensile strength after the two-stage aging treatment improved great, showing values of up to $294.46 \mathrm{MPa}$. For the two-stage aging process, the best mechanical properties were obtained at $275^{\circ} \mathrm{C}$ for $12 \mathrm{~min}+200^{\circ} \mathrm{C}$ for $8 \mathrm{~h}$, where hardness values of $82.56 \mathrm{HV}$ and tensile strength of $294.46 \mathrm{MPa}$ were obtained compared to the values of $78.9 \mathrm{HV}$ and $268.35 \mathrm{MPa}$ that were achieved during the T6_SSAT process (aging at $200^{\circ} \mathrm{C}$ for $8.25 \mathrm{~h}$ ).

In brief, this basic investigation of the microstructure, phase precipitation, and mechanical properties after various aging treatments helped to reveal the strengthening mechanisms of ZM6 aircraft wheel work pieces. The optimized deformation parameters and crack propagation mechanism will be further investigated in the future. 
Author Contributions: Conceptualization, J.F.; methodology, J.F.; validation, J.F.; validation, S.C.; formal analysis, J.F.; data curation, S.C.; writing—original draft, S.C.; writing—review and editing, J.F.; funding acquisition, J.F. All authors have read and agreed to the published version of the manuscript.

Funding: This research was funded by the Natural Science Foundation of Shaanxi Province (No. 2020JQ-769), the National Natural Science Foundation of China (No. 51905427), the Graduate Innovation Program of Xi'an Shiyou University (YCS21211070), and the Natural Science Basic Research Program of Shaanxi Province (No. 2021JM-403).

Institutional Review Board Statement: Not applicable.

Informed Consent Statement: Not applicable.

Data Availability Statement: Data are available in a publicly accessible repository that does not issue DOIs. Publicly available datasets were analyzed in this study.

Acknowledgments: The authors would like to thank Yongtang Li in the College of Material Science and Engineering at the Taiyuan University of Science and Technology (TYUST) for providing the JMatPro software. The authors would like to thank Hui Zhao in Xi'an Shiyou University for the funding and experimental supports.

Conflicts of Interest: The authors declare no conflict of interest.

\section{References}

1. Esgandari, B.A.; Mehrjoo, H.; Nami, B.; Miresmaeili, S.M. The effect of Ca and RE elements on the precipitation kinetics of Mg ${ }_{17} \mathrm{Al}_{12}$ phase during artificial aging of magnesium alloy AZ91. Mater. Sci. Eng. A 2011, 528, 5018-5024. [CrossRef]

2. Yan, B.; Dong, X.; Ma, R.; Chen, S.; Pan, Z.; Ling, H. Effects of heat treatment on microstructure, mechanical properties and damping capacity of Mg-Zn-Y-Zr alloy. Mater. Sci. Eng. A 2014, 594, 168-177. [CrossRef]

3. Zhang, J.; Liu, S.; Wu, R.; Hou, L.; Zhang, M. Recent developments in high-strength Mg-RE-based alloys: Focusing on Mg-Gd and Mg-Y systems. J. Magnes. Alloys 2018, 6, 277-291. [CrossRef]

4. Wang, B.J.; Luan, J.Y.; Xu, D.K.; Sun, J.; Li, C.Q.; Han, E.H. Research progress on the corrosion behavior of magnesium lithium-based alloys: A review. Acta Metall. Sin. 2019, 32, 1-9. [CrossRef]

5. Chen, Y.H.; Wang, L.P.; Feng, Y.C.; Wang, L.; Guo, E.J. Effect of Al content on hot tearing behaviour of Mg-xAl2Ca-2Sm alloys. Mater. Sci. Technol. 2019, 35, 116-126. [CrossRef]

6. Fu, J.; Lin, W.H.; Chen, Z.R.; Wang, K.Q. Electronic and elastic properties of $\mathrm{CaMg}_{2}$ alloy phase under various pressures by Density Functional Theory. In MATEC Web of Conferences-2016CBNCM; EDP Sciences: Les Ulis, France, 2017; Volume 88, p. 03003.

7. Fu, J.; Guo, J.K.; Bai, H.; Lin, W.H. Structural and elastic properties of CaMg 2 Laves phase by Y-parameter and Reuss-Voigt-Hill methods. IOP Conf. Ser. Mater. Sci. Eng. 2018, 423, 012052. [CrossRef]

8. Zheng, K.Y.; Dong, J.; Zeng, X.Q. Effect of pre-deformation on aging characteristics and mechanical properties of a Mg-Gd-Nd-Zr alloy. Mater. Sci. Eng. A 2008, 491, 103-109. [CrossRef]

9. Lin, D.; Wang, L.; Liu, Y.; Cui, J.Z.; Le, Q.C. Effects of plastic deformation on precipitation behavior and tensile fracture behavior of Mg-Gd-Y-Zr alloy. Trans. Nonferrous Metals Soc. 2011, 21, 2160-2167. [CrossRef]

10. Fu, P.H.; Peng, L.M.; Jiang, H.Y.; Chang, J.W.; Zhai, C.Q. Effects of heat treatments on the microstructures and mechanical properties of Mg-3Nd-0.2Zn-0.4Zr (wt.\%) alloy. Mater. Sci. Eng. A 2008, 486, 183-192.

11. Ohishi, K.; Hono, K.; Shin, K.S. Effect of pre-aging and $\mathrm{Al}$ addition on age-hardening and microstructure in $\mathrm{Mg}-6 \mathrm{wt} \% \mathrm{Zn}$ alloys. Mater. Sci. Eng. A 2008, 496, 425-433. [CrossRef]

12. Xu, S.W.; Mastumoto, N.; Kamado, S.; Honma, T.; Kojima, Y. Effect of pre-aging treatment on microstructure and mechanical properties of hot compressed Mg-9Al-1Zn alloy. Mater. Sci. Eng. A 2009, 517, 354-360. [CrossRef]

13. Paliwal, M.; Das, S.K.; Kim, J.; Jung, I.H. Diffusion of Nd in hcp Mg and interdiffusion coefficients in Mg-Nd system. Scr. Mater. 2015, 108, 11-14. [CrossRef]

14. Young, L. Grain Refinement of Magnesium. Ph.D. Thesis, The University of Queensland, Brisbane, Australia, 2002.

15. Polmear, I.J. Magnesium alloys and applications. Mater. Sci. Technol. 1994, 10, 1-14. [CrossRef]

16. Fu, P.H.; Peng, L.M.; Jiang, H.Y.; Zhai, C.Q.; Gao, X.; Nie, J.F. Zr-Containing Precipitates in Mg-3wt $\%$ Nd-0.2wt\%Zn-0.4wt $\%$ Zr Alloy during Solution Treatment at $540{ }^{\circ}$ C. Mater. Sci. Forum 2007, 546-549, 97-100. [CrossRef]

17. Guo, J.K.; Li, Y.X.; Fu, J. Researchon Design and improvement of the investment casting process for the ring-shaped magnesium alloy based on Procast software. IOP Conf. Ser. Mater. Sci. Eng. 2018, 382, 042006. [CrossRef]

18. Lan, M.; Mishrak, R.; Balogh, M.P.; Peng, L.; Luo, A.A.; Sachdev, A.K.; Ding, W. Effect of Zn on the microstructure evolution of compressed Mg-3Nd(-Zn)-Zr (wt.\%) alloys. Mater. Sci. Eng. A 2012, 543, 12-21.

19. Hao, Z.; Du, Z.; Yin, Z.; Zhang, X. Effect of hot compression and aging treatment on microstructure and mechanical properties of Mg-6Zn-1Zr-1.5Y alloy. Rare Metal Mater. Eng. 2013, 42, 84-88.

20. Nie, F.J.; Muddle, C.B. Characterisation of strengthening precipitate phases in a Mg-Y-Nd alloy. Acta Mater. 2000, 48, 1691-1703. [CrossRef] 
21. Zhang, C.C.; Wang, H.Y.; Min, Z.; Wang, C.; Li, J.H.; Yang, Z.Z.; Jiang, Q.C. Microstructure and tensile properties of AZ61 alloy sheets processed by high-ratio extrusion with subsequent direct aging treatment. Materials 2018, 11, 895. [CrossRef] [PubMed]

22. Mao, P.; Yu, B.; Liu, Z.; Wang, F.; Ju, Y. First-principles calculations of structural, elastic and electronic properties of AB2 type intermetallics in Mg-Zn-Ca-Cu alloy. J. Magnes. Alloy 2013, 1, 256-262. [CrossRef]

23. Song, B.; Wang, C.; Guo, N.; Pan, H.; Xin, R. Improving tensile and compressive properties of an extruded AZ91 rod by the combined use of torsion deformation and aging treatment. Materials 2017, 10, 280. [CrossRef]

24. Mao, P.; Yu, B.; Liu, Z.; Wang, F.; Ju, Y. Mechanical, electronic and thermodynamic properties of $\mathrm{Mg}_{2} \mathrm{Ca}$ laves phase under high pressure: A first-principles calculation. Comput. Mater. Sci. 2014, 88, 61-70. [CrossRef]

25. Spigarelli, S.; Cabibbo, M.; Evangelista, E.; Talianker, M.; Ezersky, V. Analysis of the creep behaviour of a thixoformed AZ91 magnesium alloy. Mater. Sci. Eng. A 2000, 289, 172-181. [CrossRef]

26. Cui, Y.; Shi, Y.S.; Zheng, J.; Yan, Z.M.; Zhang, J.S.; Zhang, Z.M.; Wang, Q.; Xue, Y. Influence of heat treatment on the tensile properties and fatigue properties of Mg-8.8Gd-3.5Y-1.5Zn-0.5Zr alloy. Mater. Res. Express 2021, 8, 056518. [CrossRef]

27. Barylski, A.; Aniołek, K.; Dercz, G.; Kupka, M.; Matuła, I.; Kaptacz, S. The sclerometrical, mechanical, and wear behavior of Mg-Y-Nd magnesium alloy after deep cryogenic treatment combined with heat treatment. Materials 2021, 14, 1218. [CrossRef] [PubMed]

28. Yuan, J.W.; Li, T.; Zhang, K.; Li, X.G.; Li, Y.J.; Ma, M.L.; Shi, G.L.; Du, Z.W.; Liu, W.; Peng, Y.G. Precipitation behavior of $\mathrm{Mg}-7 \mathrm{Gd}-3 \mathrm{Y}-2 \mathrm{Zn}-0.5 \mathrm{Zr}$ alloy during isothermal aging. Materials 2021, 14, 1737. [CrossRef]

29. Rong, W.; Wu, Y.; Zhang, Y.; Sun, M.; Chen, J.; Peng, L.; Ding, W. Characterization and strengthening effects of $\gamma^{\prime}$ precipitates in a high-strength casting Mg-15Gd-1Zn-0.4Zr (wt.\%) alloy. Mater. Charact. 2017, 126, 1-9. [CrossRef]

30. Zeng, G.; Liu, C.M.; Gao, Y.H.; Jiang, S.N.; Yu, S.L.; Chen, Z.Y. Effects of T5 treatment on microstructure and mechanical properties at elevated temperature of AZ80-Ag alloy. Materials 2019, 12, 3214. [CrossRef] [PubMed]

31. Yuan, J.; Li, T.; Zhang, K.; Li, M.; Li, X.; Li, Y.; Ma, M.; Shi, G. Effect of Zn content on the microstructures, mechanical properties, and damping capacities of Mg-7Gd-3Y-1Nd-0.5Zr based alloys. J. Alloys Compd. 2019, 773, 919-926. [CrossRef]

32. Ullmann, M.; Kittner, K.; Prahl, U. Hot deformation and dynamic recrystallisation behaviour of twin-roll cast Mg-6.8Y-2.5Zn0.4Zr magnesium alloy. Materials 2021, 14, 307. [CrossRef] [PubMed]

33. Sivapragash, M.; Lakshminarayanan, P.R.; Karthikeyan, R.; Hanumantha, M.; Bhatt, R.R. Hot deformation behavior of ZE41A magnesium alloy. Mater. Des. 2008, 29, 860-866. [CrossRef]

34. Luo, A.A.; Powell, B.R.; Balogh, M.P. Creep and microstructure of magnesium-aluminum-calcium based alloys. Metall. Mater. Trans. A 2002, 33, 567-574. [CrossRef]

35. Suzuki, M.; Sato, H.; Maruyama, K.; Oikawa, H. Creep deformation behavior and dislocation substructures of Mg-Y binary alloys. Mater. Sci. Eng. A 2001, 319, 751-755. [CrossRef]

36. Unigovski, Y.; Keren, Z.; Eliezer, A.; Gutman, E.M. Creep behavior of pure magnesium and Mg-Al alloys in active environments. Mater. Sci. Eng. A 2005, 398, 188-197. [CrossRef]

37. Milicka, K.; Dobe, F. Creep behaviour of a magnesium alloy AS21 and its fibre-strengthened composite. J. Alloys Compd. 2004, 378, 167-171. [CrossRef]

38. Mordike, B.L. Creep resistant magnesium alloys. Mater. Sci. Eng. A 2002, 324, 103-112. [CrossRef]

39. Regev, M.; Aghion, E.; Rosen, A.; Bamberger, M. Creep studies of coarse-grained AZ91D magnesium castings. Mater. Sci. Eng. A 1998, 252, 6-16. [CrossRef]

40. Lü, Y.; Wang, Q.; Zeng, X.; Ding, W.; Zhai, C.; Zhu, Y. Effects of rare earths on the microstructure properties and fracture behavior of Mg-Al alloys. Mater. Sci. Eng. A 2000, 278, 66-76. [CrossRef]

41. Lu, S.H.; Wu, D.; Chen, R.S.; Han, E.H. The effect of twinning on dynamic recrystallization behavior of Mg-Gd-Y alloy during hot compression. J. Alloys Compd. 2019, 803, 277-290. [CrossRef]

42. Dębski, A.; Terlicka, S.; Gąsior, W.; Gierlotka, W.; Pęska, M.; Dworecka-Wójcik, J.; Polański, M. Calorimetric studies of magnesiumrich Mg-Pd alloys. Materials 2021, 14, 680. [CrossRef]

43. Chang, J.W.; Fu, P.H.; Guo, X.W.; Peng, L.M.; Ding, W.J. The effects of heat treatment and zirconium on the corrosion behaviour of Mg-3Nd-0.2Zn-0.4Zr (wt.\%) alloy. Corros. Sci. 2007, 49, 2612-2627. [CrossRef] 